\title{
Mechanical and microstructural characterisation of SiC- and SiBNC-fibre reinforced CMCs manufactured via PIP method before and after exposure to air
}

\author{
Enrico Klatt*, Alexander Frass, Martin Frieß, Dietmar Koch, Heinz Voggenreiter \\ Institute of Structures and Design, Department Ceramic Structures and Composites, German Aerospace Center (DLR), Pfaffenwaldring 38-40, 70569 Stuttgart, \\ Germany
}

Received 24 November 2011; received in revised form 7 May 2012; accepted 18 May 2012

Available online 12 June 2012

\begin{abstract}
Non-oxide CMCs based on pyc-coated $\mathrm{SiC}$-fibres (Tyranno SA3 ${ }^{\mathrm{TM}}$ ) as well as novel amorphous ceramic fibres in the quaternary system $\mathrm{Si}-\mathrm{B}-\mathrm{C}-\mathrm{N}$ (named SiBNC-fibres) were manufactured via polymer infiltration and pyrolysis process. Two different fibre architectures were applied: $0 \mid 90^{\circ}$ unidirectional (UD) cross-ply and $0 \mid 90^{\circ}$ plain weave fabric layer. UD cross-ply reinforced CMCs exhibit much more uniformly distributed filaments leading to better infiltration efficiency in resin transfer moulding process. Bending strength and fracture behaviour are strongly influenced by fibre architecture: UD cross-ply reinforced CMCs show higher bending strengths and less non-linear behaviour compared to plain weave fibre reinforcement. In tensile test there is no evidence of an influence of fibre architecture. Mechanical properties of unexposed $\mathrm{SiC}_{\mathrm{pyc}} / \mathrm{SiCN}$ and $\mathrm{SiBNC}_{\mathrm{pyc}} / \mathrm{SiCN}$ strongly correlate with fibre properties. After exposure to air $\left(T=1100^{\circ} \mathrm{C}, 20 \mathrm{~h}\right)$, a significant decrease of mechanical properties could be observed, caused by complete oxidation of pyc-fibre coating interfered with silica formation.
\end{abstract}

(C) 2012 Elsevier Ltd. All rights reserved.

Keywords: Composites; Fibres; Interfaces; Mechanical properties; Fracture

\section{Introduction}

Ceramic matrix composites (CMC) exhibit high specific strength, high temperature resistance as well as damage tolerant behaviour. Therefore they are attractive candidate materials for structural application in hot gas environments e.g. for gas turbine or combustors components. ${ }^{1-11}$ There are several processing routes for $\mathrm{CMC}$ materials such as gas phase processing route (chemical vapour infiltration, CVI), ceramic processing route (slurry infiltration, SI/high pressure sintering, HPS) and liquid phase processing routes (reactive melt infiltration, RMI and polymer infiltration and pyrolysis, PIP) as described extensively elsewhere. ${ }^{12-17}$ The latter PIP-process, ceramic matrix is derived from organometallic pre-ceramic precursors such as polysilanes, polycarbosilanes, polysilazanes or

\footnotetext{
* Corresponding author. Tel.: +49 7116862 627; fax: +49 7116862227.

E-mail address: enrico.klatt@dlr.de (E. Klatt).
}

polysiloxanes. ${ }^{18,19}$ This work is focussed on polysilazane precursor yielding in amorphous silicon carbonitride $(\mathrm{SiCN})$ or crystalline silicon carbide $(\mathrm{SiC})$ and silicon nitride $\left(\mathrm{Si}_{3} \mathrm{~N}_{4}\right)$ phases, depending on pyrolysis conditions such as temperature and atmosphere. ${ }^{20-23}$ Conversion of preceramic precursors to ceramic material is intrinsically tied to increase of density and volume shrinkage. ${ }^{16,19,24}$ Commercially available preceramic Si-precursors have a ceramic yield in the range of 30-50 vol.\%. Hence, after pyrolysis the CMC material exhibits high porosity leading to poor inter-laminar shear strength and low thermal conductivity. ${ }^{25,26}$ To densify the ceramic matrix, several reinfiltration and pyrolysis cycles (PIP-cycles) can be applied. Depending on fibre volume content and ceramic yield of preceramic precursor, between five and ten PIP-cycles are required to obtain porosities $<10 \mathrm{vol}$. $\%$.

Concerning fibre reinforcement, this work focussed on two non-oxide ceramic fibre types: commercially available polycrystalline SiC-fibres type Tyranno SA3 ${ }^{\mathrm{TM}}$ (UBE Industries Ltd., Yamaguchi, Japan) as well as novel amorphous fibres 
in the quaternary system $\mathrm{Si}-\mathrm{B}-\mathrm{C}-\mathrm{N}$. First $\mathrm{SiBNC}$-fibres were developed by Baldus et al. in the early 90s in laboratory scale. Fibres were melt-spun using methyldichlorosilylaminodichloroborane (MADB) polymeric precursor. In literature, the synthesis of this polymer and its properties have been reported extensively. ${ }^{27-30}$ After melt-spinning, fibres were cured with trichlorosilane (TCS), and finally pyrolysed and sintered at temperatures above $1600^{\circ} \mathrm{C}$ to obtain ceramic fibres. The composition of these novel fibres is approximately $\mathrm{SiBN}_{3} \mathrm{C}$, but named SiBNC is this work. Some of the outstanding properties attributed to $\mathrm{SiBNC}$-fibres which were reported elsewhere are thermal stability of the amorphous phase to temperatures as high as $1900^{\circ} \mathrm{C},{ }^{30-32}$ a very low oxidation rate for a non-oxide material, ${ }^{31,32}$ fibre strengths being similar to those of polycrystalline $\mathrm{SiC}$-fibres and creep resistance that is superior to these of polycrystalline fibres. ${ }^{29,30}$ Riedel et al. reported, that SiBNCfibres exhibit a stage III creep rate below detectible measurement levels. ${ }^{33}$ Recently, it was reported that fibre strengths as well as oxidation resistance was not as good as reported in previously work. ${ }^{34}$ Furthermore, recent creep results showed that creep resistance of SiBNC-fibres is similar to polycrystalline SiCfibres such as Hi-Nicalon type $\mathrm{S}$ or Tyranno SA $3^{\mathrm{TM}} .3^{35}$ Within the scope of German funded project SiPEVe (funded by Federal Ministry of Education and Research (BMBF); contract no. 03X3514H), the development of SiBNC-fibres was continued at Fraunhofer Institute for Silicate Research (ISC; Würzburg, Germany) and the fibre production was up scaled to an annual fibre mass output of $\sim 5-10 \mathrm{~kg}$ (status: 2010).

Due to the fact, that for SiBNC-fibre type only rovings were available, fibre preforms based on $\mathrm{SiC}$ - and SiBNC-fibres were manufactured via filament winding technique to compare both fibre types. The fibre reinforcement architecture consisted of alternating unidirectional (UD) cross-ply layers with an orientation of $0 \mid 90^{\circ}$. Non-oxide CMCs are intrinsically not oxidation resistant. To improve oxidation resistance, a low specific surface is advantageous. Therefore this work is focussed on relatively dense CMC materials (porosity $\sim 5$ vol. \%). According to He and Hutchinson, in case of a CMC material with a dense matrix (Young's modulus of the matrix is in the same range like Young's modulus of the fibre), fibres need to be equipped with a weak interphase (so called weak interphase composite, WIC) to obtain high specific strength and damage tolerant behaviour. ${ }^{36}$ Therefore, pyrolytic carbon (pyc) was deposited on Tyranno SA $3^{\mathrm{TM}}$ as well as SiBNC-fibres. Both pyc-coated fibre types were used to manufacture CMC materials via PIP-process. Finally, mechanical properties of CMC materials (before and after exposure to air: $1100^{\circ} \mathrm{C}, 20 \mathrm{~h}$ ), which are related to fibre properties, were compared to each other and discussed.

Next to the comparison of $0 \mid 90^{\circ}$ UD cross-ply layer reinforced CMCs based on Tyranno SA3 ${ }^{\mathrm{TM}}$ and SiBNC-fibres, the influence of fibre architecture with respect to mechanical and microstructural properties was investigated for Tyranno SA3 ${ }^{\mathrm{TM}}$ fibre type. Thus, SiC-fibre preforms based on layers of commercially available plain weave fabrics were manufactured, mechanically and microstructurally characterised and compared with the results of $\mathrm{SiC}$-fibre based CMCs with $0 \mid 90^{\circ} \mathrm{UD}$ crossply layer fibre reinforcement.
Table 1

Properties of SiC-fibre type Tyranno SA $3^{\mathrm{TM}}$ (UBE Industries Ltd., Japan) and SiBNC-fibres (SiPEVe, Germany).

\begin{tabular}{llcc}
\hline Property & Dimension & Tyranno SA3 & $\mathrm{SiBNC}^{\mathrm{TM} 37}$ \\
\hline Fibre diameter & $\mu \mathrm{m}$ & 7.5 & $8-12$ \\
Density & $\mathrm{g} / \mathrm{cm}^{3}$ & 3.10 & 2.00 \\
Oxygen content & $\mathrm{wt} \%$ & $<1$ & $<1$ \\
Tensile strength & $\mathrm{GPa}$ & 2.8 & 1.7 \\
Strain to failure & $\%$ & 0.7 & $0.8-1.2$ \\
Young's modulus & $\mathrm{GPa}$ & 380 & 150 \\
\hline
\end{tabular}

Summarising, the aim of this study was to establish correlations between fibre properties and mechanical properties of non-oxide SiC-fibre (type Tyranno $\mathrm{SA} 3^{\mathrm{TM}}$ ) as well as novel SiBNC-fibre reinforced CMC materials manufactured via PIPprocess before and after exposure to air.

\section{Experimental}

\subsection{Raw materials}

Two different fibre types were used as fibre reinforcement (Table 1): Polycrystalline SiC-fibres type Tyranno $\mathrm{SA}^{\mathrm{TM}}$ grade 3 (named Tyranno $\mathrm{SA} 3^{\mathrm{TM}}$ ) and amorphous SiBNC-fibres. SiBNC-fibres used in this work were produced between 2009 and 2010 and provided by Fraunhofer Institute for Silicate Research (ISC; Würzburg, Germany). This fibre type was available as roving on spools (roving lengths between 100 and $500 \mathrm{~m}$ ) with a number of 500 filaments/roving. Fabrics of SiBNC-fibre type are currently not available. SiC-fibre type Tyranno SA3 ${ }^{\mathrm{TM}}$ is commercially available and was provided by UBE Industries Ltd. (Yamaguchi, Japan). For fibre preform manufacturing, SiC-roving (type: S1I16PX, 1600 filaments/roving) as well as plain weave fabric (type: PSA-S17I16PX, mass per unit area: $260 \mathrm{~g} / \mathrm{m}^{2}$ ) were used.

As preceramic precursor material for PIP-process, a commercially available polysilazane named PSZ20, supplied by Clariant Advanced Materials GmbH (Sulzbach, Germany) was used.

\subsection{Fibre preform preparation}

In this study, two different fibre reinforcement architectures, unidirectional (UD) cross-ply layer and layer of plain weave fabric, were investigated (Fig. 1). For fibre roving raw material (available for Tyranno SA3 ${ }^{\mathrm{TM}}$ and SiBNC-fibre), a fibre architecture of UD cross-ply layer with an alternating orientation of $0^{\circ}$ and $90^{\circ}$ was applied by filament winding technique. As winding core, a graphitic mandrel with a dimension of $L \times W \times H=155 \mathrm{~mm} \times 155 \mathrm{~mm} \times 20 \mathrm{~mm}$ was used. To decrease the potential of curving of the plate during processing, a symmetrical layer stack up of cross-ply layer was applied. Thus, the fibre architecture consisted of 16 UD cross-ply layer for SiBNC- and SiC-fibre type, whereas the 8th and 9th layer had the same orientation. After filament winding, the fibre preforms were coated with pyc via rapid-chemical vapour infiltration process (r-CVI) by CVT GmbH \& Co. KG (Halblech, Germany). 

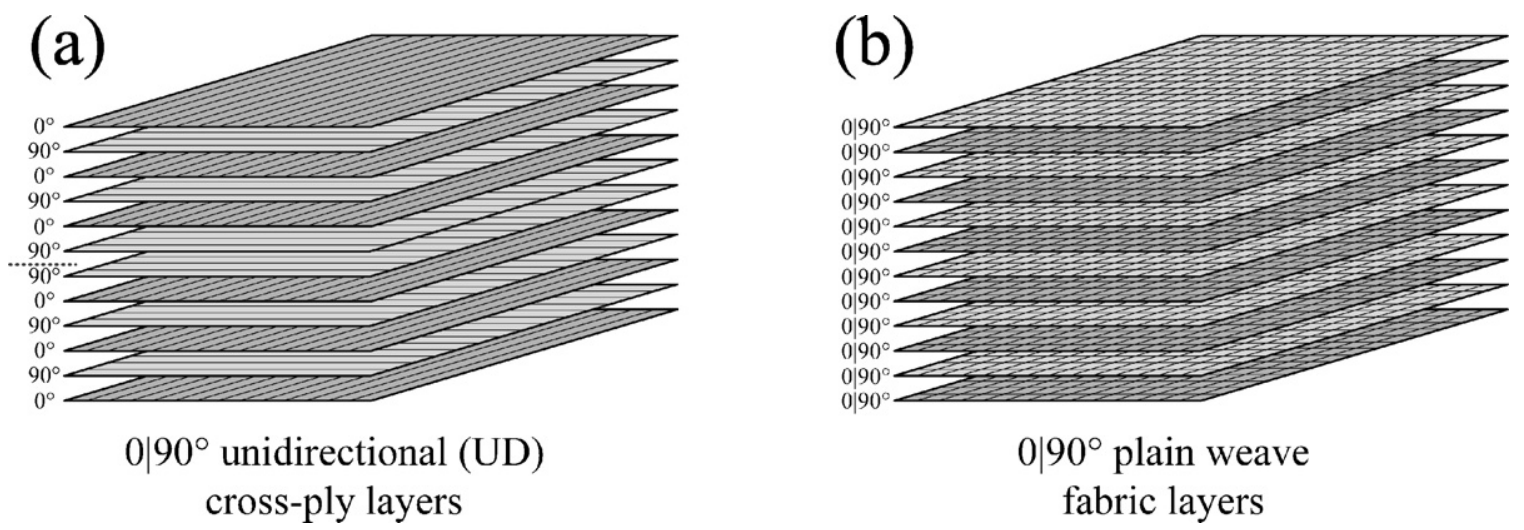

Fig. 1. Two different approaches for fibre reinforcement architecture: (a) UD cross-ply layers $\left(0 \mid 90^{\circ}\right)$ by filament winding technique for SiBNC-and SiC-fibres and (b) layers of plain weave fabrics $\left(0 \mid 90^{\circ}\right)$ for SiC-fibres.

The desizing of the fibres occurred in situ during the r-CVI process.

The Tyranno SA3 ${ }^{\mathrm{TM}}$ fibre fabric raw material was cut $(L \times W=300 \mathrm{~mm} \times 90 \mathrm{~mm})$ and desized $\left(600^{\circ} \mathrm{C}\right.$, air). Pyc-fibre coating was applied to single plain weave fabric layer by CVIprocess at Schunk Kohlenstofftechnik GmbH (Heuchelheim, Germany).

\subsection{CMC manufacturing process}

To manufacture SiBNC- and SiC-fibre reinforced CMCs, polymer infiltration and pyrolysis process (PIP) was used (Fig. 2). Pyc-coated SiBNC- and SiC-fibre preforms based on filament winding technique as well as $\mathrm{SiC}$ plain weave fabrics were infiltrated with PSZ20 via resin transfer moulding process (RTM). The fibre volume content was adjusted to $\sim 30$ vol. $\%$.

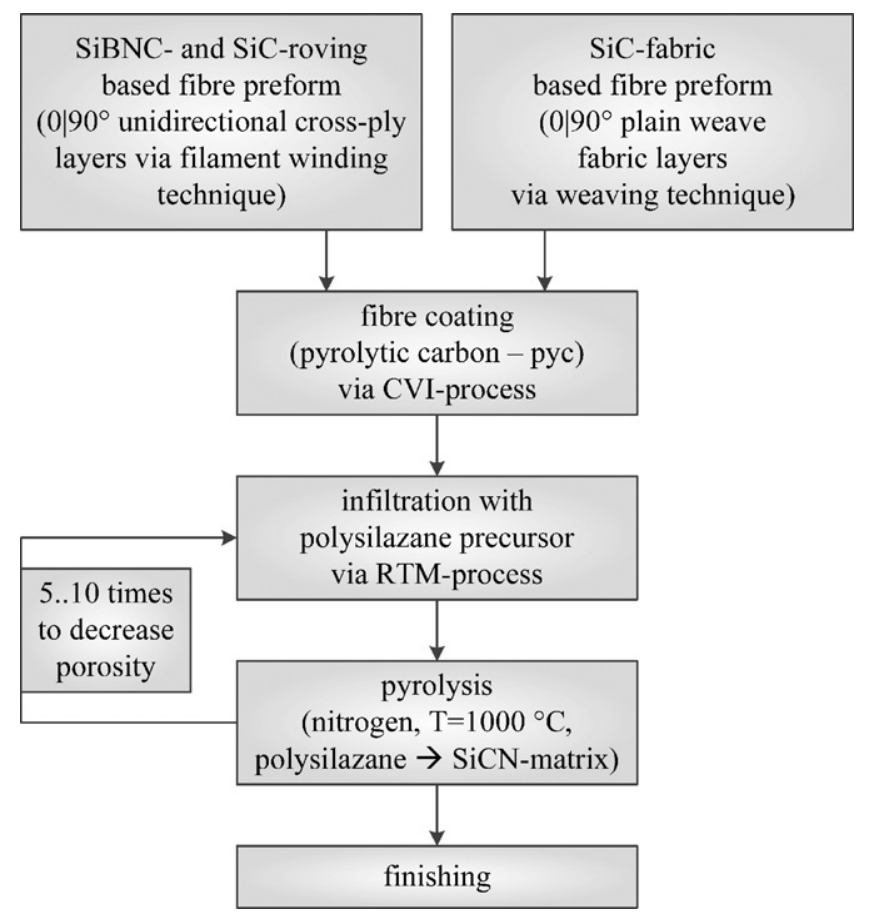

Fig. 2. PIP-process to manufacture SiBNC- and SiC-fibre reinforced CMCs.
After infiltration, the pyrolysis process was conducted subsequently at $1000^{\circ} \mathrm{C}$ under nitrogen atmosphere. During pyrolysis, the cured PSZ20 precursor converted into an amorphous silicon carbonitride $(\mathrm{SiCN})$ matrix. This conversion is combined with mass loss and shrinkage. The shrinkage of the matrix is constrained by fibre reinforcement leading to pores and cracking in the matrix. To densify the matrix, several reinfiltration and pyrolysis cycles had been performed. In this study, the target for open porosity was $\sim 5 \mathrm{vol} . \%$. To hit the target, for $0 \mid 90^{\circ} \mathrm{UD}$ cross-ply (SiBNC- and SiC-fibre) and for plain weave fabric (SiC-fibre) reinforced $\mathrm{CMCs}$, in total six and nine infiltration and pyrolysis cycles (PIP-cycles) had been performed, respectively.

\subsection{Characterisation and testing}

\subsubsection{Precursor characterisation}

To determine the mass yield of PSZ20, thermogravimetric analysis (TGA) had been performed with cured precursor (taken from RTM-process) by means of simultaneous thermal analysis (STA 409, Netzsch-Gerätebau GmbH, Selb, Germany) under different flowing $(100 \mathrm{ml} / \mathrm{min})$ atmospheres: nitrogen, argon and laboratory air with a water vapour content of $\sim 2.3 \%$. The heating rate was $10 \mathrm{~K} / \mathrm{min}$ for a temperature range of $20-1400^{\circ} \mathrm{C}$.

The density of cured and pyrolysed PSZ20 was measured by means of heliumpycnometer (type: Accupyc 1330, Micromeritics Instrument Corporation, Norcross, GA, USA) according to ISO 1183. Cured precursor, which was taken from RTM-process, showed no visible pores. Thus, it was measured as bulk material. Instead of cured status, pyrolysed PSZ20 showed many pores and cracks. To decrease the potential of measuring error caused by closed pores, pyrolysed PSZ20 was pulverised and sieved (mesh size: $0.16 \mathrm{~mm} \times 0.25 \mathrm{~mm}$ ) before measuring.

For PIP-process, the ceramic yield (given in vol.\%) of a precursor is necessary to estimate the number of PIP-cycles to obtain a certain porosity. The ceramic yield for a pyrolysis temperature of $1000^{\circ} \mathrm{C}$ under different atmospheres was calculated with the results of TGA and density of cured and pyrolysed PSZ20 as follows:

$K=K_{\mathrm{TGA}} / 100 \mathrm{wt} . \% \times \rho_{\text {cured }} / \rho_{\text {pyrolysed }} \times 100 \mathrm{vol} . \%$ 
where $K$ is the ceramic yield (vol.\%), $K_{\mathrm{TGA}}$ is the mass yield (wt. $\%$ ) from TGA, $\rho_{\text {cured }}$ and $\rho_{\text {pyrolysed }}$ are the density $\left(\mathrm{g} / \mathrm{cm}^{3}\right)$ of cured and pyrolysed precursors, respectively.

\subsubsection{CMC characterisation}

To determine the evolution of density and open porosity of CMC materials during PIP-process, Archimedes method according to DIN 51918 was applied after each pyrolysis step.

Pore diameter distribution in SiC-fibre reinforced CMCs with different fibre architectures $\left(0 \mid 90^{\circ} \mathrm{UD}\right.$ cross-ply layer and layer of plain weave fabric with six and nine PIP-cycles, respectively) measured by means of mercury intrusion porosimetry (type: Pascal 240, CE Instruments, Hindley Green, United Kingdom) according to DIN 66133. The pressure range was between 0-200 MPa. Hence, pore diameter between $10 \mathrm{~nm}$ and $100 \mu \mathrm{m}$ could be determined. For calculation of pore diameter, cylindrical pore shape model and a mercury contact angle of $140^{\circ}$ was used.

Prior to test sample preparation, manufactured CMC plates were cut in half and one half was exposed to laboratory air at $1100^{\circ} \mathrm{C}$ for $20 \mathrm{~h}$. The water vapour content was measured at $\sim 2.7 \%$. Finally, three-point(3-pt.)-bending test samples $(L \times W \times H=75 \mathrm{~mm} \times 8 \mathrm{~mm} \times 2 \mathrm{~mm})$ as well as tensile test samples $(L \times W \times H=120 \mathrm{~mm} \times 8 \mathrm{~mm} \times 2 \mathrm{~mm}$, waisted sample with sample width in clamping region of $15 \mathrm{~mm}$ ) were cut from unexposed and exposed CMC materials.

For mechanical characterisation, six samples of unexposed and exposed CMC materials were tested in 3-pt.-bending test (according to DIN EN 658-3) as well as in tensile test (according to DIN EN 658-1). In case of $0 \mid 90^{\circ} \mathrm{UD}$ cross-ply layer reinforced CMC materials, the fibre orientation in outer face layer was in loading direction for both, 3-pt.-bending as well as tensile test. In case of plain weave fabric fibre reinforcement, the fibre orientation was $0 \mid 90^{\circ}$ with respect to test direction. To determine the strain to failure and Young's modulus in tensile test, strain gauges were applied to the samples. For both, 3-pt.-bending and tensile tests, the test speed was $1 \mathrm{~mm} / \mathrm{min}$.

CMC materials were examined before and after exposure to air by field emission-scanning electron microscope (FE-SEM; type: Zeiss Ultra Plus, Carl Zeiss NTS GmbH, Oberkochen, Germany) operating at $5 \mathrm{kV}$. The SEM is equipped with energy-dispersive spectroscopy (EDS) system (X-Max detector $20 \mathrm{~mm}^{2}$, Oxford Instruments, Tubney Wood, United Kingdom).

To investigate the mass change of $0 \mid 90^{\circ} \mathrm{UD}$ cross-ply layer SiBNC- and SiC-fibre based CMC materials during exposure to air, TGAs (same equipment as for precursor characterisation) were performed in flowing laboratory air $(100 \mathrm{ml} / \mathrm{min})$ at $700{ }^{\circ} \mathrm{C}$ and $1100^{\circ} \mathrm{C}$ with a dwelling time of $20 \mathrm{~h}$. The heating rate was $5 \mathrm{~K} / \mathrm{min}$.

\section{Results and discussion}

\subsection{Precursor characterisation}

In Fig. 3 TGA curves of cured (taken from RTM-process) and dried $\left(110^{\circ} \mathrm{C}, 1 \mathrm{~h}\right)$ PSZ20 under different atmospheres (air, argon, nitrogen) are given for a temperature range of

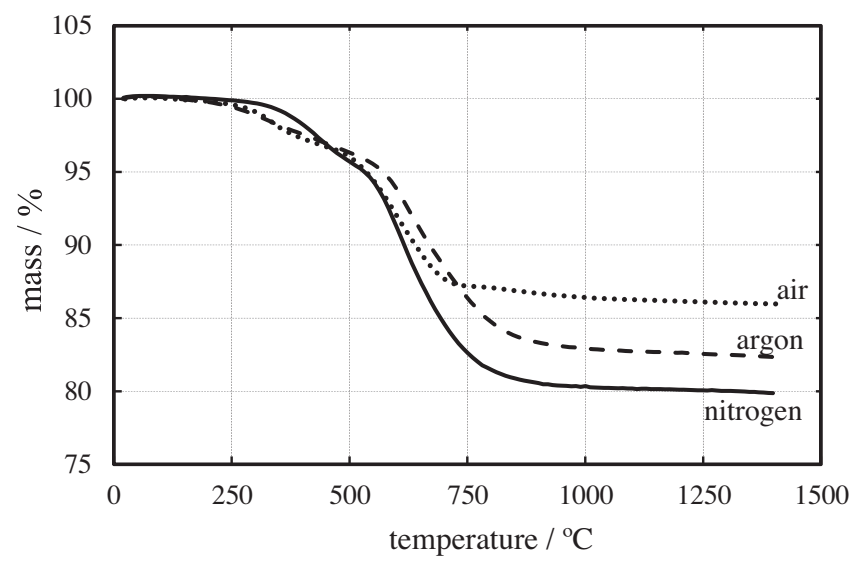

Fig. 3. TGA of cured polysilazane precursor (PSZ20, Clariant $\mathrm{GmbH}$ ) under different atmospheres (temperature range: $20-1400^{\circ} \mathrm{C}$, heating rate: $10 \mathrm{~K} / \mathrm{min}$ ).

20-1400 ${ }^{\circ} \mathrm{C}$. Mass loss started at $\sim 250^{\circ} \mathrm{C}$ (curing temperature in RTM-process). The main mass loss occurred in two stages: first stage of mass loss is between $250^{\circ} \mathrm{C}$ and $550^{\circ} \mathrm{C}$ followed by a second stage of mass loss with a higher mass decrease gradient. The mass loss is a result of elimination of organic groups evaporated as methane, ethylene, ammonia, and hydrogen. Finally, the mass loss converged asymptotically to mass yield (given in wt.\%). Mass yield as well as temperature level where the main mass loss is finished is dependent of atmosphere. The main mass loss is finished at $\sim 700^{\circ} \mathrm{C}$ and $\sim 900^{\circ} \mathrm{C}$ for air and argon/nitrogen, respectively. The results for density of PSZ20 in cured and pyrolysed status, mass yield (from TGA) as well as ceramic yield (calculated with Eq. (1)) are summarised in Table 2. From processing point of view, a high ceramic yield is desirable. Nevertheless, the slightly higher ceramic yield of pyrolysed polysilazane in air compared to argon/nitrogen is faced to less oxidation resistance of ceramic matrix composition $\left(\mathrm{SiCNO} / \mathrm{SiO}_{2}\right)$ compared to $\mathrm{SiCN}$ which is formed under argon/nitrogen atmosphere. Within the measurement uncertainty, the ceramic yield of polysilazane under argon/nitrogen pyrolysis atmosphere is nearly the same. Considering economy, nitrogen was chosen as pyrolysis atmosphere in this work.

\subsection{Characterisation of density and porosity of CMC materials}

Fig. 4 shows the evolution of density and open porosity of SiBNC- and SiC-fibre based CMCs with different fibre architectures $\left(0 \mid 90^{\circ} \mathrm{UD}\right.$ cross-ply layer and layer of plain weave fabric) during PIP-process. The density increased for all CMC materials, whereas the open porosity decreased. The delta increase of density as well as the delta decrease of open porosity between two pyrolysis cycles becomes smaller with cumulative number of pyrolysis cycles. Thus, the efficiency of reinfiltration and pyrolysis cycle with respect to decreasing open porosity and increasing density reduces constantly.

The comparison of SiBNC- and SiC-fibre based CMCs with $0 \mid 90^{\circ}$ UD cross-ply layer indicates, that after six PIP-cycles, open porosity is similar and at a low level $(5.2 \mathrm{vol} . \%$ and 
Table 2

Properties of polysilazane precursor (PSZ20, Clariant $\mathrm{GmbH}$ ) for pyrolysis temperature of $1000{ }^{\circ} \mathrm{C}$ in different atmospheres.

\begin{tabular}{|c|c|c|c|c|}
\hline Pyrolysis atmosphere & Density $^{\mathrm{a}}$ of cured ${ }^{\mathrm{b}}$ precursor $\left(\mathrm{g} / \mathrm{cm}^{3}\right)$ & Density ${ }^{\mathrm{a}}$ of ceramic $\left(\mathrm{g} / \mathrm{cm}^{3}\right)$ & Mass yield (wt.\%) & Ceramic yield $K($ vol. $\%)$ \\
\hline Nitrogen & 1.120 & 2.216 & 80.4 & 40.6 \\
\hline Argon & 1.120 & 2.245 & 82.9 & 41.4 \\
\hline Air & 1.120 & 2.125 & 86.4 & 45.5 \\
\hline
\end{tabular}

a Density measured by heliumpycnometer according to ISO 1183.

b Cured precursor taken from RTM-process.

4.8 vol.\% for $\mathrm{SiBNC}_{\mathrm{pyc}} / \mathrm{SiCN}$ and $\mathrm{SiC}_{\mathrm{pyc}} / \mathrm{SiCN}$, respectively). Six PIP-cycles are very low compared to reported 12-16 required PIP-cycles to obtain a similar porosity for $0 \mid 90^{\circ}$ UD cross-ply layer reinforced CMCs. ${ }^{39}$ This assumes a very good infiltration efficiency in RTM-process. The difference in open porosity after first pyrolysis might be caused by slightly higher fibre volume content or better first RTM-infiltration for SiC-fibre based CMC. The difference in density, $2.03 \mathrm{~g} / \mathrm{cm}^{3}$ and $2.38 \mathrm{~g} / \mathrm{cm}^{3}$ for crossply $\mathrm{SiBNC}_{\mathrm{pyc}} / \mathrm{SiCN}$ and $\mathrm{SiC}_{\mathrm{pyc}} / \mathrm{SiCN}$, respectively, results from lower fibre density of $\operatorname{SiBNC}\left(2.00 \mathrm{~g} / \mathrm{cm}^{3}\right)$ compared to Tyranno SA3 $\left(3.10 \mathrm{~g} / \mathrm{cm}^{3}\right)($ ref. Table 1$)$.

The comparison of $\mathrm{SiC}_{\mathrm{pyc}} / \mathrm{SiCN} \mathrm{CMC}$ materials with different fibre architectures $\left(0 \mid 90^{\circ} \mathrm{UD}\right.$ cross-ply layer vs. $0 \mid 90^{\circ}$ plain weave fabric layer) points out that the infiltration efficiency is highly dependent on fibre architecture. For fibre reinforcement based on plain weave fabrics, three more PIP-cycles are needed to obtain approximately the same open porosity (6.3 vol.\%) compared to $\mathrm{SiC}_{\mathrm{pyc}} / \mathrm{SiCN}$ with $0 \mid 90^{\circ} \mathrm{UD}$ cross-ply layer fibre reinforcement $(4.8 \mathrm{vol} . \%)$. In case of $0 \mid 90^{\circ}$ UD cross-ply layer fibre reinforcement, with respect to fibre volume content the filaments are well distributed within the layer. Homogeneous fibre volume content leads to a very good RTM-infiltration performance without any pores after curing (open porosity $<1$ vol.\%) due to homogeneous capillarity. In case of fibre reinforcement based on layer of plain weave fabric, a strong ondulation of the rovings associated with filament bundles and gussets are present (Fig. 5). With respect to fibre volume content, the filaments are not well distributed within a single plain weave fabric layer: Within a roving, the fibre volume content was determined at

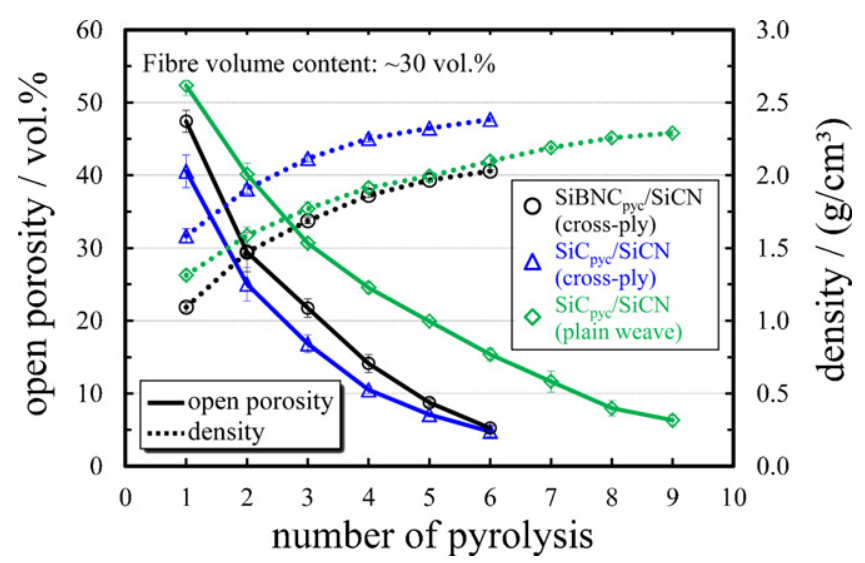

Fig. 4. Evolution of open porosity and density (mean values and standard deviation $=$ error bars) of SiBNC- and SiC-fibre reinforced CMCs in PIP-process with different fibre architectures $\left(0 \mid 90^{\circ}\right.$ UD cross-ply layer and plain weave fabric) measured by Archimedes method according to DIN 51918. $\sim 71 \mathrm{vol} . \%$, whereas the fibre volume content of CMC plate was adjusted to $\sim 30 \mathrm{vol} . \%$ in RTM-process. In case of inhomogeneous fibre volume content like for plain weave fabric based fibre architecture, the capillarity is inhomogeneous which leads to a poor RTM-infiltration performance where not all pores are filled with PSZ20 precursor. This results in a higher number of PIP-cycles to obtain a desired open porosity.

The microstructure of $0 \mid 90^{\circ}$ UD cross-ply layer and plain weave fabric layer reinforced $\mathrm{SiC}_{\mathrm{pyc}} / \mathrm{SiCN}$ after final pyrolysis (Fig. 5) with a similar open porosity shows, that in $0 \mid 90^{\circ}$ UD cross-ply layer reinforced CMC the pores are well distributed and no pore agglomeration is present. In contrast to that, $\mathrm{CMCs}$ with a fibre architecture based on layer of plain weave fabric exhibit agglomerations of pores which are located in gussets of plain weave fabric layer. The average pore size seems to be larger than for $0 \mid 90^{\circ} \mathrm{UD}$ cross-ply layer reinforced CMCs.

Pore size distribution of $\mathrm{SiC}_{\mathrm{pyc}} / \mathrm{SiCN}$ with $0 \mid 90^{\circ} \mathrm{UD}$ crossply layer as well as plain weave fabric fibre architecture was measured by mercury intrusion porosimetry (Fig. 6). $0 \mid 90^{\circ}$ UD cross-ply layer reinforced $\mathrm{SiC}_{\mathrm{pyc}} / \mathrm{SiCN}$ (Fig. 6a) shows a bimodal pore size distribution with pore diameters of $75-100 \mu \mathrm{m}$ and $\sim 50 \mathrm{~nm}$ and a relative pore volume of $8.1 \mathrm{vol} . \%$ and 7.3 vol. $\%$, respectively. The average pore diameter is $181 \mathrm{~nm}$ (Table 3). In contrast to $0 \mid 90^{\circ}$ UD cross-ply layer reinforcement, plain weave fabric layer reinforced $\mathrm{SiC}_{\text {pyc }} / \mathrm{SiCN}$ (Fig. 6b) exhibits only one significant peak with a pore diameter of $\sim 4 \mu \mathrm{m}$ and a relative pore volume of $14.7 \mathrm{vol} . \%$. The average pore diameter is $1205 \mathrm{~nm}$ which is much higher ( factor 6.7 ) compared to $0 \mid 90$ UD cross-ply layer reinforcement. This correlates quite well with SEM-micrographs: $\mathrm{SiC}_{\mathrm{pyc}} / \mathrm{SiCN}$ with plain weave fabric layer reinforcement (Fig. 5b) showed larger pores than CMC material with $0 \mid 90^{\circ} \mathrm{UD}$ cross-ply layer reinforcement (Fig. 5a).

The results of mercury intrusion porosimetry (average pore diameter and open porosity) are summarised in Table 3 and faced to open porosity measured by Archimedes method. Open porosities measured by means of mercury intrusion porosimetry are slightly smaller than values measured by Archimedes method which might be caused by measuring errors.

\subsection{Mechanical properties of CMC materials}

Fig. 7 shows typical 3-pt.-bending stress-strain curves (note: strain was calculated from displacement) of $\mathrm{SiBNC}-\left(0 \mid 90^{\circ} \mathrm{UD}\right.$ cross-ply) and $\mathrm{SiC}$-fibre (0|90 $90^{\circ} \mathrm{UD}$ cross-ply and plain weave) reinforced CMCs before and after exposure to air $\left(T=1100^{\circ} \mathrm{C}\right.$, $t=20 \mathrm{~h}$ ). After exposure to air, all CMC materials showed a significant decrease of bending strength which was $69 \%, 77 \%$ 

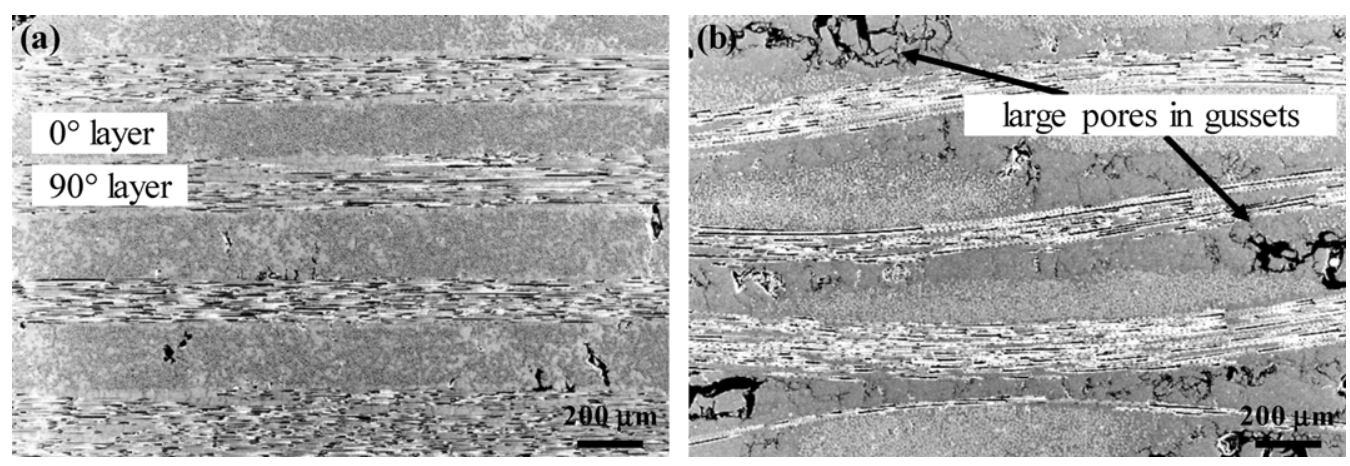

Fig. 5. SEM-micrographs (SE) of polished cross sections for SiC-fibre (TyrannoSA3 ${ }^{\mathrm{TM}}$ ) reinforced CMCs with different fibre reinforcement architectures: (a) $0 \mid 90^{\circ}$ UD cross-ply layer reinforcement after six PIP-cycles, (b) $0 \mid 90^{\circ}$ plain weave fabric reinforcement after nine PIP-cycles.

(a)

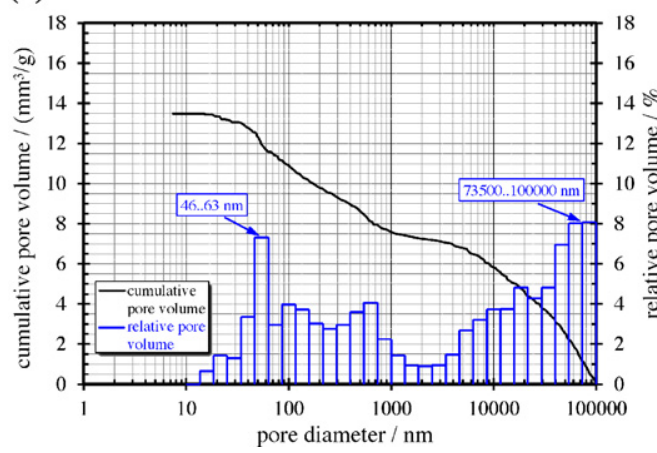

(b)

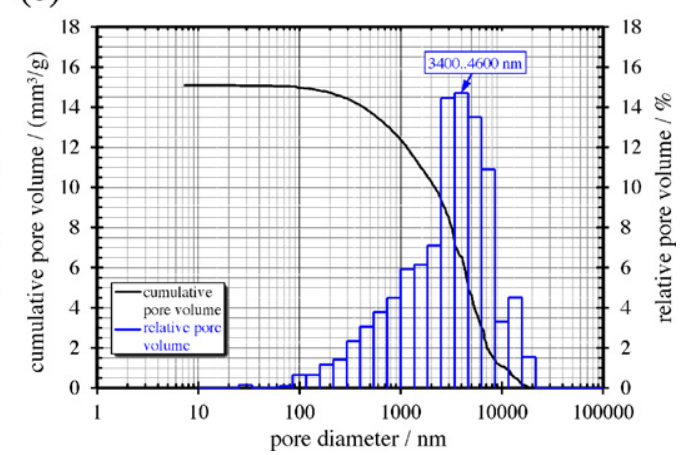

Fig. 6. Pore size distribution in $\mathrm{SiC}_{\mathrm{pyc}} / \mathrm{SiCN}$ with different fibre architecture: (a) $0 \mid 90^{\circ} \mathrm{UD}$ cross-ply layer and (b) plain weave fabric after six and nine PIP-cycles, respectively, measured by means of mercury intrusion porosimetry according to DIN 66133.

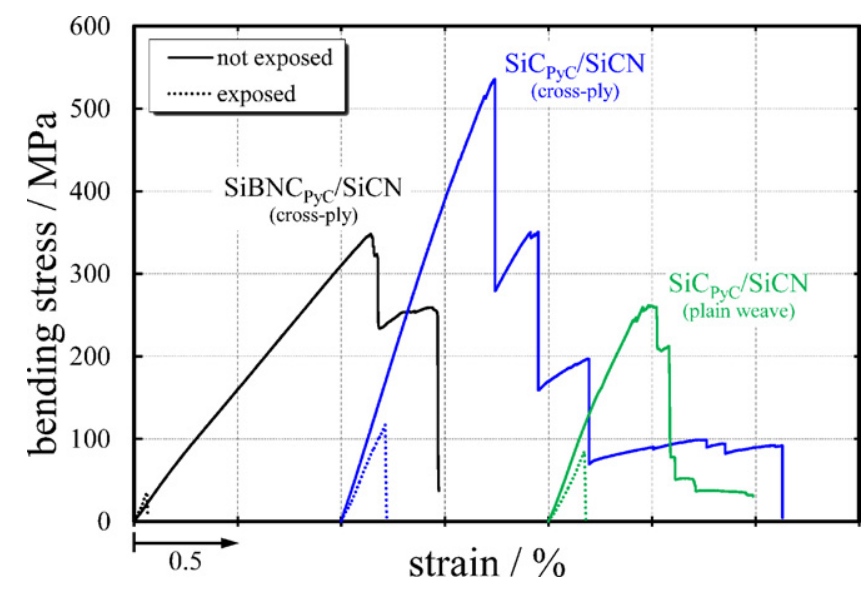

Fig. 7. Typical 3-pt.-bending stress-strain curves of $0 \mid 90^{\circ}$ UD cross-ply layer and plain weave fabric SiBNC- and SiC-fibre reinforced CMCs before and after exposure to air $\left(T=1100^{\circ} \mathrm{C}, t=20 \mathrm{~h}\right)$. Note: Offset of curves for better clarity. and $85 \%$ for $\mathrm{SiC}_{\mathrm{pyc}} / \mathrm{SiCN}$ (plain weave), $\mathrm{SiC}_{\mathrm{pyc}} / \mathrm{SiCN}$ (crossply) and $\mathrm{SiBNC}_{\mathrm{pyc}} / \mathrm{SiCN}$ (cross-ply), respectively.

For cross-ply layer reinforced CMCs, the bending strength of unexposed $\mathrm{SiC}_{\mathrm{pyc}} / \mathrm{SiCN}$ is $57 \%$ higher than of $\mathrm{SiBNC}_{\mathrm{pyc}} / \mathrm{SiCN}$. That strongly correlates with fibre tensile strength (ref. Table 1), where SiC-fibre type Tyranno SA3 ${ }^{\mathrm{TM}}(2.8 \mathrm{GPa})$ has a $65 \%$ higher tensile strength than SiBNC-fibre $(1.7 \mathrm{GPa})$. Furthermore, bending strength is strongly influenced by fibre architecture: For $\mathrm{SiC}_{\mathrm{pyc}} / \mathrm{SiCN}$ (plain weave) the bending strength is $47 \%$ lower than for $\mathrm{SiC}_{\mathrm{pyc}} / \mathrm{SiCN}$ (cross-ply). The main reason is that for $\mathrm{SiC}_{\mathrm{pyc}} / \mathrm{SiCN}$ (cross-ply) the tensile loaded UD reinforced outer layer, which carries most of the applied load in bending test, exhibits a fibre volume content in loading direction $(\sim 30 \mathrm{vol} . \%)$ which is double compared to outer layer of plain weave fabric reinforcement $(\sim 15$ vol. $\%)$.

The fracture behaviour of $0 \mid 90^{\circ}$ UD cross-ply layer reinforced CMCs is a different one compared to these with plain weave fabric fibre reinforcement: $\mathrm{SiC}_{\mathrm{pyc}} / \mathrm{SiCN}$ (plain weave)

Table 3

Pore size and porosity measured by means of mercury intrusion porosimetry in comparison to open porosity measured by Archimedes method.

\begin{tabular}{lllll}
\hline $\mathrm{CMC}$ material & No. of PIP-cycles & Average pore diameter ${ }^{\mathrm{a}}(\mathrm{nm})$ & Open porosity $^{\mathrm{a}}\left(\right.$ vol. $\left.^{\circ}\right)$ & Open porosity $^{\mathrm{b}}($ vol.\%) \\
\hline $\mathrm{SiC}_{\mathrm{pyc}} / \mathrm{SiCN}$ (cross ply) & 6 & 181 & 3.27 & 4.32 \\
$\mathrm{SiC}_{\mathrm{pyc}} / \mathrm{SiCN}$ (plain weave) & 9 & 1205 & 3.59 & 5.23 \\
\hline
\end{tabular}

\footnotetext{
${ }^{a}$ Measured by means of mercury intrusion porosimetry according to DIN 66133 and calculated with pore shape model "cylindrical". Average pore diameter is defined as four times total pore volume divided by the surface area.

b Measured by Archimedes method according to DIN 51918.
} 
showed a more incisive non-linear behaviour compared to $\mathrm{SiC}_{\mathrm{pyc}} / \mathrm{SiCN}$ (cross-ply). The reason is that in case of plain weave fabric fibre reinforcement, cracks were initiated at lower stress levels on the outer face of the tensile loaded layer in regions with less fibre reinforcement like matrix dominated regions (gussets) or in regions with fibre orientation being perpendicular to loading direction (due to plain weave fibre architecture). These cracks were stopped or deflected by fibre reinforcement being in loading direction. In case of $0 \mid 90^{\circ}$ UD cross-ply layer reinforced $\mathrm{SiC}_{\mathrm{pyc}} / \mathrm{SiCN}$, in tensile loaded outer layer there are no matrix dominated regions or fibres with an orientation perpendicular to loading direction. Thus, cracks occurred at significant higher stress levels compared to plain weave fabric fibre reinforcement. Furthermore, initiated cracks in the matrix were stopped or deflected immediately by fibres which are not ondulated and orientated in loading direction with respect to outer layer. Thus, $0 \mid 90^{\circ}$ UD cross-ply layer reinforced CMCs exhibit less significant non-linear behaviour compared to plain weave fabric layer reinforced CMCs.

After reaching bending strength, an abrupt decrease of bending stress was determined for both, cross-ply layer and plain weave fabric fibre architecture. The way of decrease of bending stress after reaching bending strength strongly correlated with fibre architecture. In case of cross-ply layer reinforcement, the stepwise decrease combined with a further increase of bending stress is much more significant compared to plain weave fabric fibre reinforcement. The reason is that for $0 \mid 90^{\circ}$ UD cross-ply layer reinforced CMCs there is a difference in fibre architecture with respect to ability of carrying load: One layer consists of fibres orientated all in loading direction (fibre dominated region with a good ability for carrying load) followed by a second layer consisting of fibres orientated all perpendicular to loading direction (matrix dominated region with a poor ability of load carrying). If cracks reach a layer with fibre orientation in loading direction, fibres carry the load and cracks are stopped, deflected or bridged by reinforcing fibres which are equipped with a weak fibre-matrix bonding (pyc-fibre coating). Thus, a stop of bending stress decrease occurred followed by a further increase of bending stress. The bending stress declines again when fibres cannot carry the load anymore and break. Thus, the cracks propagate quickly in the next layer with a fibre orientation being perpendicular to the loading direction to the next layer with a fibre orientation in loading direction. In plain weave fabric layer reinforced CMCs, there is no clear local separation of fibres which are located in and perpendicular to loading direction compared to $0 \mid 90^{\circ}$ UD cross-ply fibre architecture. This results in less significant stepwise decrease of bending strength after reaching bending stress.

In Fig. 8, typical tensile stress-strain curves of $0 \mid 90^{\circ} \mathrm{UD}$ cross-ply layer and plain weave fabric SiBNC- and SiCfibre reinforced $\mathrm{CMCs}$ (unexposed) are given. The tensile stress-strain curves for $\mathrm{SiC}_{\mathrm{pyc}} / \mathrm{SiCN}$ with different fibre architectures (cross-ply and plain weave) look very similar. Tensile strength, Young's modulus and strain to failure are nearly the same. Thus, properties (measured in tensile test) of CMCs with similar fibre volume content are not affected significantly by different fibre architecture associated with a different degree

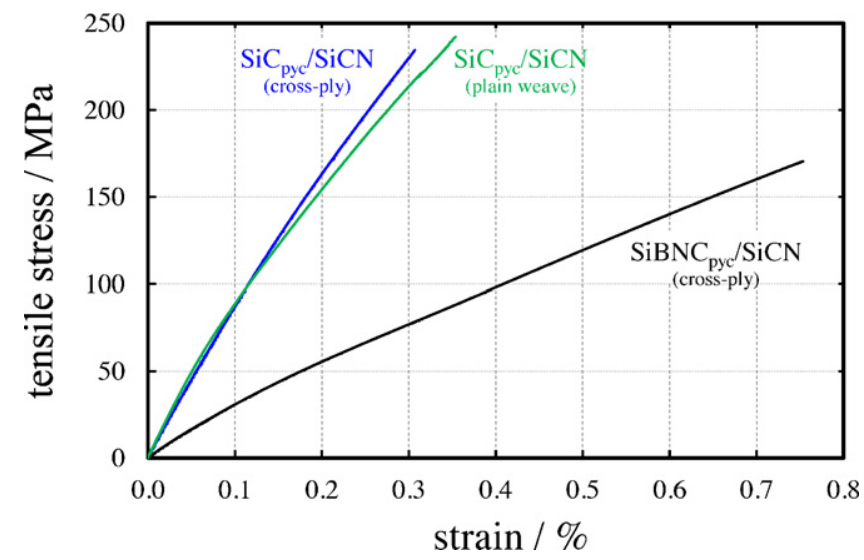

Fig. 8. Typical tensile stress-strain curves for SiBNC- and SiC-fibre reinforced $\mathrm{CMCs}$ with $0 \mid 90^{\circ} \mathrm{UD}$ cross-ply layer and plain weave fabric fibre architecture (not exposed to air).

of fibre ondulation. For $0 \mid 90^{\circ}$ UD cross-ply layer reinforced $\mathrm{CMCs}$, tensile strength and Young's modulus of $\mathrm{SiC}_{\mathrm{pyc}} / \mathrm{SiCN}$ are significantly higher (236 MPa and $87 \mathrm{GPa}$, respectively) than of $\mathrm{SiBNC}_{\mathrm{pyc}} / \mathrm{SiCN}$ (170 MPa and $32 \mathrm{GPa}$, respectively) whereas strain to failure of $\mathrm{SiC}_{\mathrm{pyc}} / \mathrm{SiCN}(0.31 \%)$ is significantly lower than of $\mathrm{SiBNC}_{\mathrm{pyc}} / \mathrm{SiCN}(0.78 \%)$. The differences in tensile strength, Young's modulus and strain to failure between fibre properties and CMC properties are given in Fig. 9a-c. The differences in CMC properties are mainly caused by different fibre properties (ref. Table 1). Nevertheless, fibre properties are partly utilised in CMCs (reduced fibre utilisation) depending on e.g. CMC manufacturing process, fibre/matrix interphase, ratio between fibre and matrix properties. For fabricated $\mathrm{Si}(\mathrm{BN}) \mathrm{C}_{\mathrm{pyc}} / \mathrm{SiCN} \mathrm{CMCs}$ via PIP, fibre properties correlate quite well with $\mathrm{CMC}$ properties (Fig. 9c).

The mechanical properties of SiBNC- and SiC-fibre reinforced CMCs with different fibre architectures $\left(0 \mid 90^{\circ}\right.$ UD cross-ply and plain weave fabric layer) before and after exposure to air $\left(T=1100^{\circ} \mathrm{C}, t=20 \mathrm{~h}\right)$ are summarised in Fig. 10 and Table 4. Bending strength, tensile strength as well as strain to failure strongly decreased after exposure to air. The decrease of tensile strength of cross-ply $\mathrm{SiBNC}_{\mathrm{pyc}} / \mathrm{SiCN}(94 \%)$ is slightly higher than of $\mathrm{SiC}_{\mathrm{pyc}} / \mathrm{SiCN}(85 \%)$ ). For $\mathrm{SiBNC}_{\mathrm{pyc}} / \mathrm{SiCN}$ (crossply), Young's modulus increased significantly (103\%) whereas for $\mathrm{SiC}_{\mathrm{pyc}} / \mathrm{SiCN}$ (cross ply and plain weave) there is no significant change in stiffness. The reasons of changes of mechanical properties after exposure to air are caused by significant microstructural changes and will be discussed later in this study (see Section 3.4).

In Fig. 11, SEM-micrographs of cracked samples (from 3-pt.-bending test) for $0 \mid 90^{\circ}$ UD cross-ply layer reinforced $\mathrm{SiBNC}_{\mathrm{pyc}} / \mathrm{SiCN}$ and $\mathrm{SiC}_{\mathrm{pyc}} / \mathrm{SiCN}$ before and after exposure to air are faced. Both unexposed CMC materials showed significant crack deflection, crack bridging and fibre pull-out (Fig. 11a and b). These energy dissipating mechanisms refer to distinct damage tolerant behaviour. $\mathrm{SiC}_{\mathrm{pyc}} / \mathrm{SiCN}$ exhibits much more multiple cracking of matrix which might be caused by higher fibre/matrix interfacial shear stresses or higher fracture energy (due to higher stress levels compared to $\mathrm{SiBNC}_{\mathrm{pyc}} / \mathrm{SiCN}$ ). 

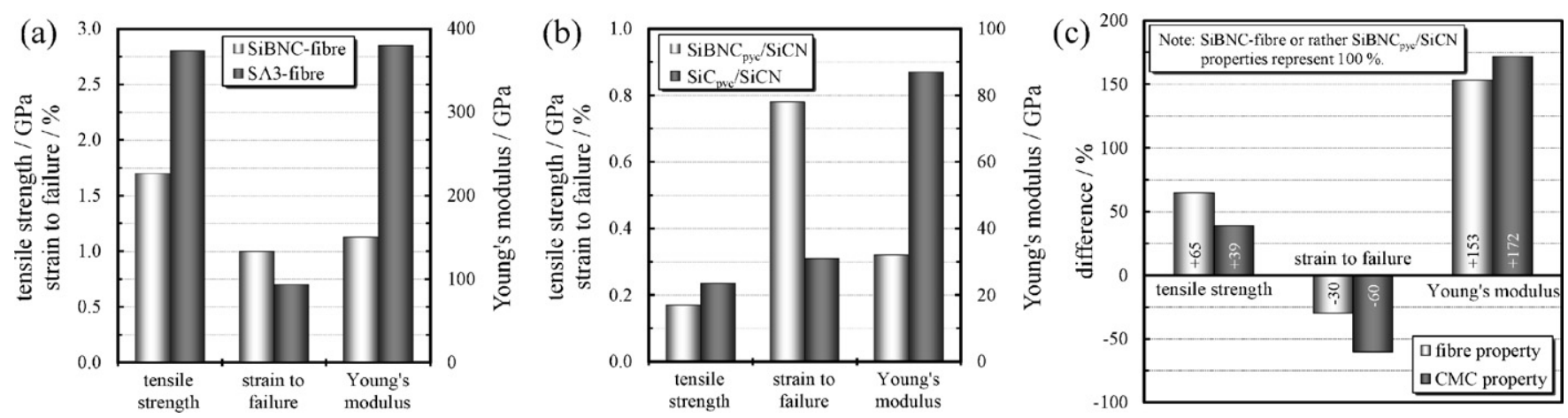

Fig. 9. Comparison of properties (strength, strain to failure and Young's modulus): (a) $\mathrm{SiBNC}$ - and $\mathrm{SiC}-\mathrm{fibre}$ properties; (b) $\mathrm{properties}$ of $\mathrm{SiBNC}$ pyc $/ \mathrm{SiCN}$ and $\mathrm{SiC}_{\mathrm{pyc}} / \mathrm{SiCN}$ and (c) relative comparison between fibre- and CMC-properties. Note: All properties refer to not exposed material status.

(a)

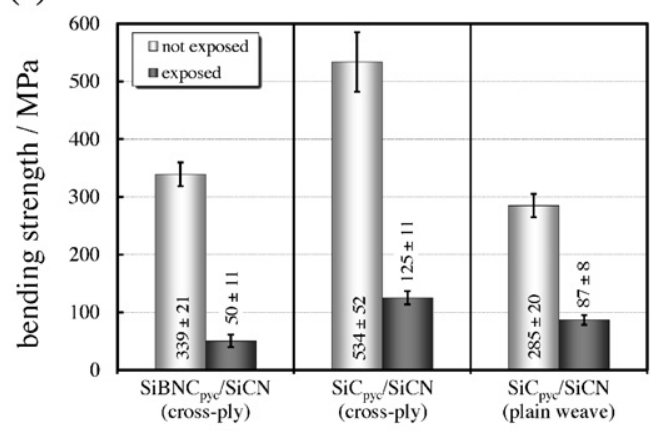

(c)

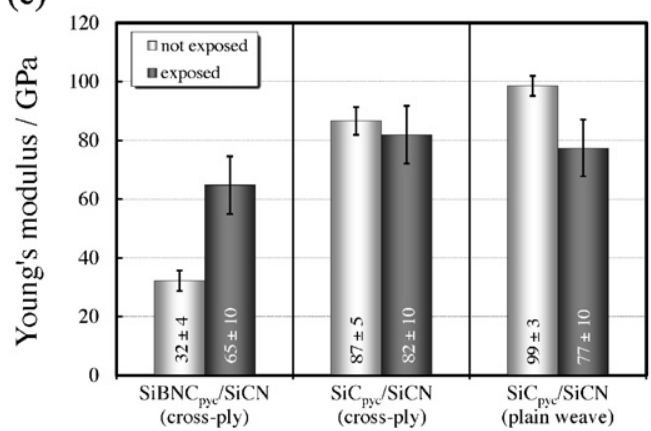

(b)

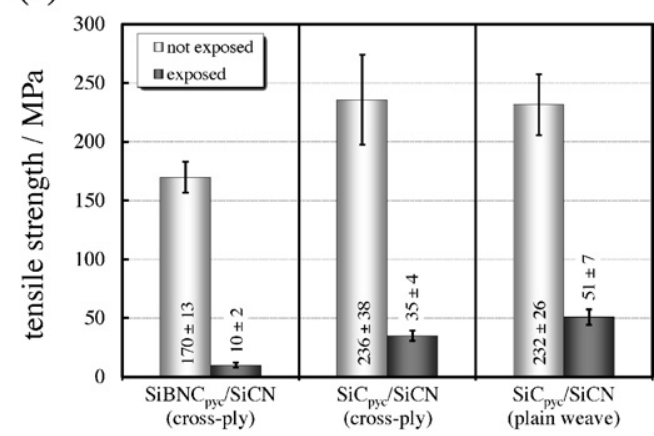

(d)

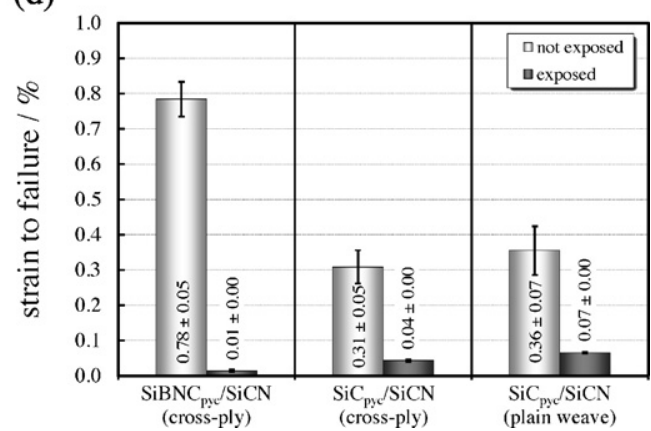

Fig. 10. Mechanical properties (mean values and standard deviation =error bars) of SiBNC- and SiC-fibre reinforced $\left(0 \mid 90^{\circ}\right.$ plain weave fabric and $0 \mid 90^{\circ}$ UD cross-ply layer reinforcement) CMCs before and after exposure to air $\left(T=1100^{\circ} \mathrm{C}, t=20 \mathrm{~h}\right)$ : (a) 3-pt.-bending strength, (b) tensile strength, (c) Young's modulus (from tensile test) and (d) strain to failure (from tensile test).

After exposure to air $\left(T=1100^{\circ} \mathrm{C}, t=20 \mathrm{~h}\right)$, fracture behaviour changed significantly: $\mathrm{SiBNC}_{\mathrm{pyc}} / \mathrm{SiCN}$ showed very brittle fracture behaviour where no crack deflection and no fibre pull-out could be observed (Fig. 11c) whereas $\mathrm{SiC}_{\mathrm{pyc}} / \mathrm{SiCN}$ showed a more damage tolerant behaviour with crack deflection and little fibre pull-out (Fig. 11d). Nevertheless, for exposed $\mathrm{SiC}_{\mathrm{pyc}} / \mathrm{SiCN}$ energy dissipating mechanisms were less significant compared to unexposed material status. The embrittlement of $\mathrm{SiBNC}_{\mathrm{pyc}} / \mathrm{SiCN}$ and $\mathrm{SiC}_{\mathrm{pyc}} / \mathrm{SiCN}$ after exposure to air might be caused by significant increase of fibre/matrix

Table 4

Summary of mechanical properties (mean values and standard deviation in brackets) of $\mathrm{SiBNC}_{\mathrm{pyc}} / \mathrm{SiCN}$ and $\mathrm{SiC}_{\mathrm{pyc}} / \mathrm{SiCN}$ with different fibre architecture (0|90 $90^{\circ} \mathrm{UD}$ cross-ply and $0 \mid 90^{\circ}$ plain weave fabric) before and after exposure to air $\left(T=1100^{\circ} \mathrm{C}, t=20 \mathrm{~h}\right)$.

\begin{tabular}{|c|c|c|c|c|c|c|c|}
\hline \multirow[t]{2}{*}{ Property } & \multirow[t]{2}{*}{ Dimension } & \multicolumn{2}{|c|}{$\mathrm{SiBNC}_{\mathrm{pyc}} / \mathrm{SiCN}$ (cross-ply) } & \multicolumn{2}{|c|}{$\mathrm{SiC}_{\mathrm{pyc}} / \mathrm{SiCN}$ (cross-ply) } & \multicolumn{2}{|c|}{$\mathrm{SiC}_{\mathrm{pyc}} / \mathrm{SiCN}$ (plain weave) } \\
\hline & & Unexposed & Exposed & Unexposed & Exposed & Unexposed & Exposed \\
\hline Bending strength & $\mathrm{MPa}$ & $339(21)$ & $50(11)$ & $534(52)$ & $125(11)$ & $285(20)$ & $87(8)$ \\
\hline Young's modulus & $\mathrm{GPa}$ & $32(4)$ & $65(10)$ & $87(5)$ & $82(10)$ & $99(3)$ & $77(10)$ \\
\hline Strain to failure & $\%$ & $0.78(0.05)$ & $0.01(0.00)$ & $0.31(0.05)$ & $0.04(0.00)$ & $0.36(0.07)$ & $0.07(0.00)$ \\
\hline
\end{tabular}



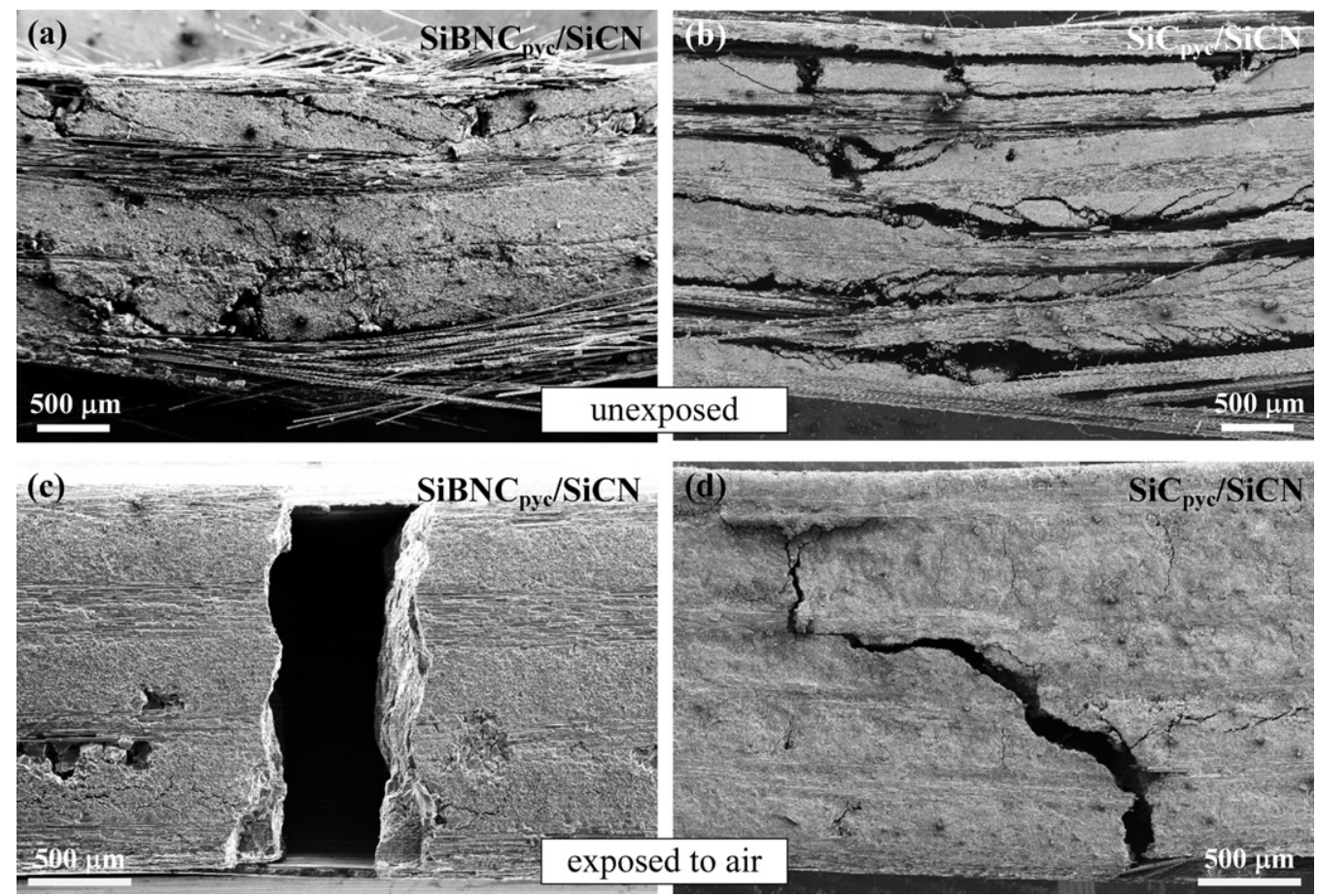

Fig. 11. SEM-micrographs (SE) of fracture behaviour for $0 \mid 90^{\circ} \mathrm{UD}$ cross-ply layer reinforced $\mathrm{SiBNC}_{\mathrm{pyc}} / \mathrm{SiCN}(\mathrm{a}, \mathrm{c})$ and $\mathrm{SiC}$ pyc $/ \mathrm{SiCN}$ (b, d) in 3-pt.-bending test: (a, b) before exposure to air, (c, d) after exposure to air $\left(T=1100^{\circ} \mathrm{C}, t=20 \mathrm{~h}\right)$.

bonding which seems to higher for $\mathrm{SiBNC}_{\text {pyc }} / \mathrm{SiCN}$ than for $\mathrm{SiC}_{\text {pyc }} / \mathrm{SiCN}$ (will be discussed more in detail in Section 3.4). Micrographs of fracture behaviour before and after exposure to air strongly correlate with mechanical properties (ref. Figs. 7, 8 and 10).

\subsection{Microstructure of CMC materials}

In Fig. 12, SEM-micrographs (SE) of polished cross sections before and after exposure to air of $0 \mid 90^{\circ} \mathrm{UD}$ cross-ply layer reinforced $\operatorname{SiBNC} C_{\text {pyc }} / \operatorname{SiCN}(\mathrm{a}, \mathrm{c})$ and $\mathrm{SiC}_{\mathrm{pyc}} / \mathrm{SiCN}(\mathrm{b}, \mathrm{d})$ are faced. Both unexposed CMC materials showed a homogeneous pyc-fibre coating (Fig. 12a and b). The pyc-coating thickness measured by SEM-micrographs was $\sim 350 \mathrm{~nm}$ and $\sim 360 \mathrm{~nm}$ for $\mathrm{SiBNC}_{\mathrm{pyc}} / \mathrm{SiCN}$ and $\mathrm{SiC}_{\mathrm{pyc}} / \mathrm{SiCN}$, respectively. No spalling or cracking of pyc-coating could be observed. The pyc-coated fibres are embedded in a relatively dense SiCN-matrix (open porosity of CMCs $\sim 5 \mathrm{vol} . \%$ ) without large pores. Nevertheless, microcracks could be observed in the matrix which result from volume shrinkage of the matrix during last pyrolysis cycle (Fig. 12a and b).

After exposure to laboratory air (Fig. 12c and d), pyc-fibre coating is completely oxidised by active oxidation resulting in the formation of gaseous carbon oxides $\left(\mathrm{CO}_{x}\right)$ according to the following equations:

$$
\begin{aligned}
& \mathrm{C}_{(\mathrm{s})}+0.5 \mathrm{O}_{2(\mathrm{~g})} \rightarrow \mathrm{CO}_{(\mathrm{g})} \\
& \mathrm{C}_{(\mathrm{s})}+\mathrm{O}_{2(\mathrm{~g})} \rightarrow \mathrm{CO}_{2(\mathrm{~g})}
\end{aligned}
$$

Next to active oxidation of carbon, passive oxidation of $\mathrm{SiC}$ and $\mathrm{SiCN}$ occurred ${ }^{40}$ which led to formation of silica $\left(\mathrm{SiO}_{2}\right)$ and gaseous carbon oxide $\left(\mathrm{CO}_{x}\right)$ or mono-nitrogen oxides $\left(\mathrm{NO}_{x}\right)$. Passive oxidation of $\mathrm{SiCN}$ is much more complex than of $\mathrm{SiC}$ because it combines oxidation features of $\mathrm{SiC}$ and silicon nitride $\left(\mathrm{Si}_{3} \mathrm{~N}_{4}\right)$. Following equations present passive oxidation of $\mathrm{SiC}$ ((4) and (5), written for stoichiometric $\mathrm{SiC})$ and $\mathrm{Si}_{3} \mathrm{~N}_{4}((6 \mathrm{a})$ and (6b) $)^{40-46}$ :

$$
\begin{aligned}
& \mathrm{SiC}_{(\mathrm{s})}+1.5 \mathrm{O}_{2(\mathrm{~g})} \rightarrow \mathrm{SiO}_{2(\mathrm{~s}, 1)}+\mathrm{CO}_{(\mathrm{g})} \\
& \mathrm{SiC}_{(\mathrm{s})}+2 \mathrm{O}_{2(\mathrm{~g})} \rightarrow \mathrm{SiO}_{2(\mathrm{~s})}+\mathrm{CO}_{2(\mathrm{~g})} \\
& \mathrm{Si}_{3} \mathrm{~N}_{4(\mathrm{~s})}+0.75 \mathrm{O}_{2(\mathrm{~g})} \rightarrow 1.5 \mathrm{Si}_{2} \mathrm{~N}_{2} \mathrm{O}_{(\mathrm{s})}+0.5 \mathrm{~N}_{2(\mathrm{~g})} \\
& \mathrm{Si}_{2} \mathrm{~N}_{2} \mathrm{O}_{(\mathrm{s})}+1.5 \mathrm{O}_{2(\mathrm{~g})} \rightarrow 2 \mathrm{Si}_{2} \mathrm{O}_{2(\mathrm{~s})}+\mathrm{N}_{2(\mathrm{~g})}
\end{aligned}
$$

To figure silica formation in $0 \mid 90^{\circ} \mathrm{UD}$ cross-ply layer reinforced $\mathrm{SiBNC}_{\text {pyc }} / \mathrm{SiCN}$ and $\mathrm{SiC}_{\mathrm{pyc}} / \mathrm{SiCN}$ after exposure to air, EDS-mappings of both CMC materials are faced in Fig. 13. Thus, only silicon $(\mathrm{Si})$ and oxygen $(\mathrm{O})$ are shown and further elements like carbon, nitrogen, or boron are neglected. Grey colour indicates the location of dedicated element in the subfigures.

For $\mathrm{SiBNC}_{\text {pyc }} / \mathrm{SiCN}$, the silica formation is much more significant than for $\mathrm{SiC}_{\text {pyc }} / \mathrm{SiCN}$ (Fig. 12c, d and Fig. 13a, b). The gap resulting from active oxidation of pyc-coating is fully closed by silica formation which is associated with a strong increase of fibre/matrix bonding. However, some pores are present in the matrix where $\mathrm{SiO}_{2}$ is present. Most of the SiBNC-fibres show no circular cross section after exposure (Fig. 12c and Fig. 13a) which might led to a significant decrease of fibre tensile strength.

Baldus et al. reported that $\mathrm{SiBNC}$-fibres formed a $\mathrm{BN} / \mathrm{SiO}_{2}$ double-layer in oxidative atmospheres at high temperatures whereas $\mathrm{SiO}_{2}$-layer is closest to the fibre surface. Boron and nitrogen evaporated as nitrogen $\left(\mathrm{N}_{2}\right)$ and diboron trioxide 

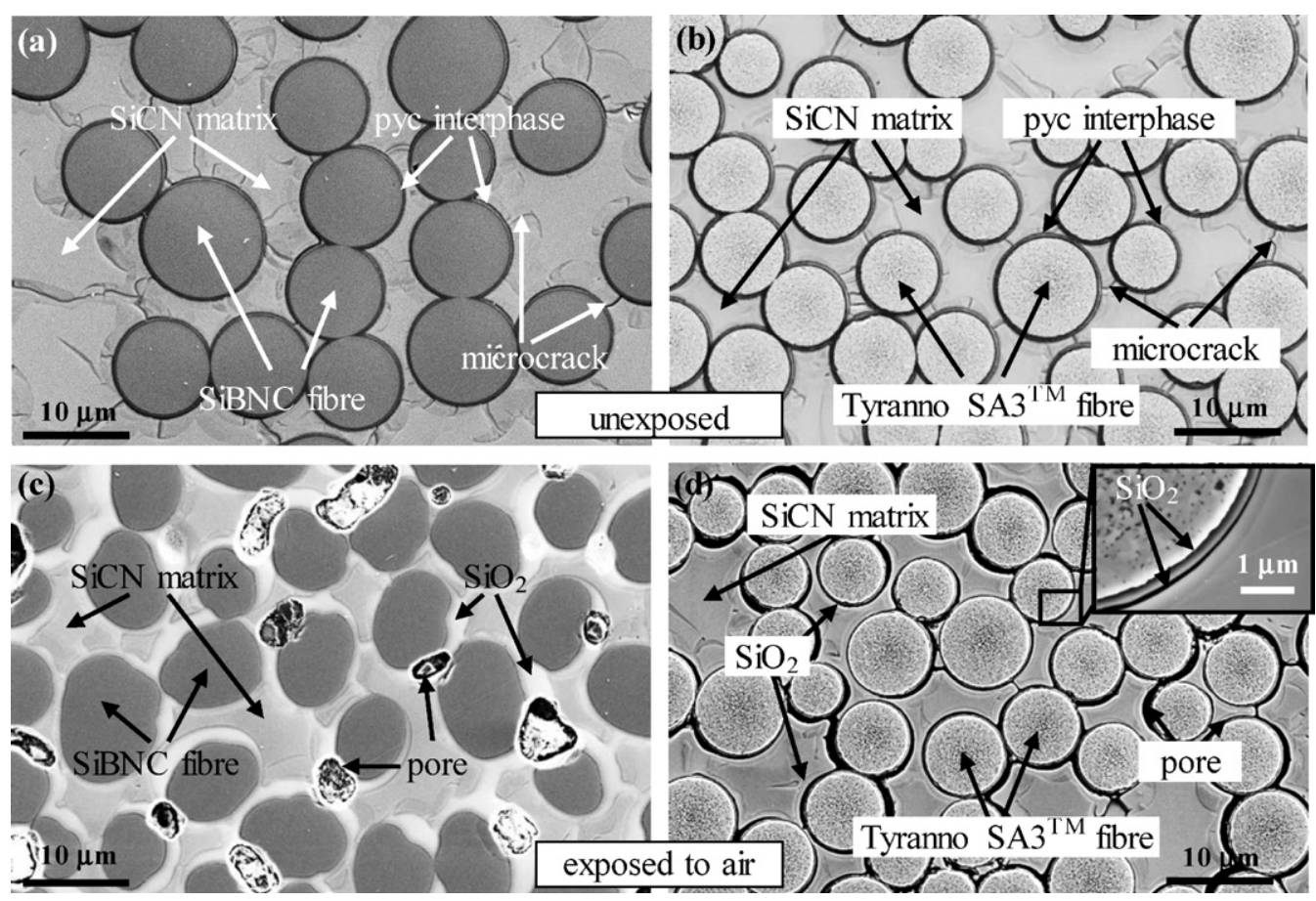

Fig. 12. SEM-micrographs (SE) of polished cross sections for $0 \mid 90^{\circ} \mathrm{UD}$ cross-ply layer reinforced $\mathrm{SiBNC}_{\mathrm{pyc}} / \mathrm{SiCN}(\mathrm{a}, \mathrm{c})$ and $\left.\mathrm{SiC} \mathrm{pyc}_{\mathrm{piCN}} / \mathrm{S}, \mathrm{d}\right)$ before $(\mathrm{a}, \mathrm{b})$ and after exposure (c, d) to air $\left(T=1100^{\circ} \mathrm{C}, t=20 \mathrm{~h}\right)$.

$\left(\mathrm{B}_{2} \mathrm{O}_{3}\right)$ which might be the reason for pores in the matrix (Fig. 12c). ${ }^{29,30} \mathrm{~B}_{2} \mathrm{O}_{3}$ is liquid above $\sim 410^{\circ} \mathrm{C}$ and undergoes vaporisation at temperatures beyond $1000-1100^{\circ} \mathrm{C}$ in dry air, but at much lower temperatures if the atmosphere contains water

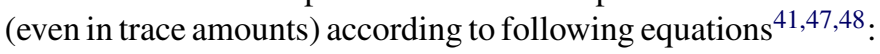

$$
\begin{aligned}
& \mathrm{B}_{2} \mathrm{O}_{3(\mathrm{l})}+\mathrm{H}_{2} \mathrm{O}_{(\mathrm{g})} \rightarrow 2 \mathrm{HBO}_{2(\mathrm{~g})} \text { at } T \geq 1000{ }^{\circ} \mathrm{C} \\
& 1.5 \mathrm{~B}_{2} \mathrm{O}_{3(\mathrm{l})}+1.5 \mathrm{H}_{2} \mathrm{O}_{(\mathrm{g})} \rightarrow\left(\mathrm{HBO}_{2}\right)_{3(\mathrm{~g})} \\
& 0.5 \mathrm{~B}_{2} \mathrm{O}_{3(\mathrm{l})}+1.5 \mathrm{H}_{2} \mathrm{O}_{(\mathrm{g})} \rightarrow \mathrm{H}_{3} \mathrm{BO}_{3(\mathrm{~g})} \text { at } T<1000{ }^{\circ} \mathrm{C}
\end{aligned}
$$

Cinibulk and Parthasarathy did further investigations on oxidised polymer-derived SiBNC-fibres. ${ }^{34}$ They found, that the formation of oxidation layers is much more complex. Microstructural analysis showed that three oxidation layers are present: The surface layer consists of $\alpha$-cristobalite, the second layer is amorphous silica and the third layer (closest to the unreacted fibre core) is a mixed layer of SiBCNO glass with boron nitride $(\mathrm{BN})$ precipitates. Similar results could be determined in $\mathrm{SiBNC}_{\text {pyc }} / \mathrm{SiCN}$ CMCs after exposure to air (Fig. 14a). Finally they found, fibre strengths degraded significantly after a short
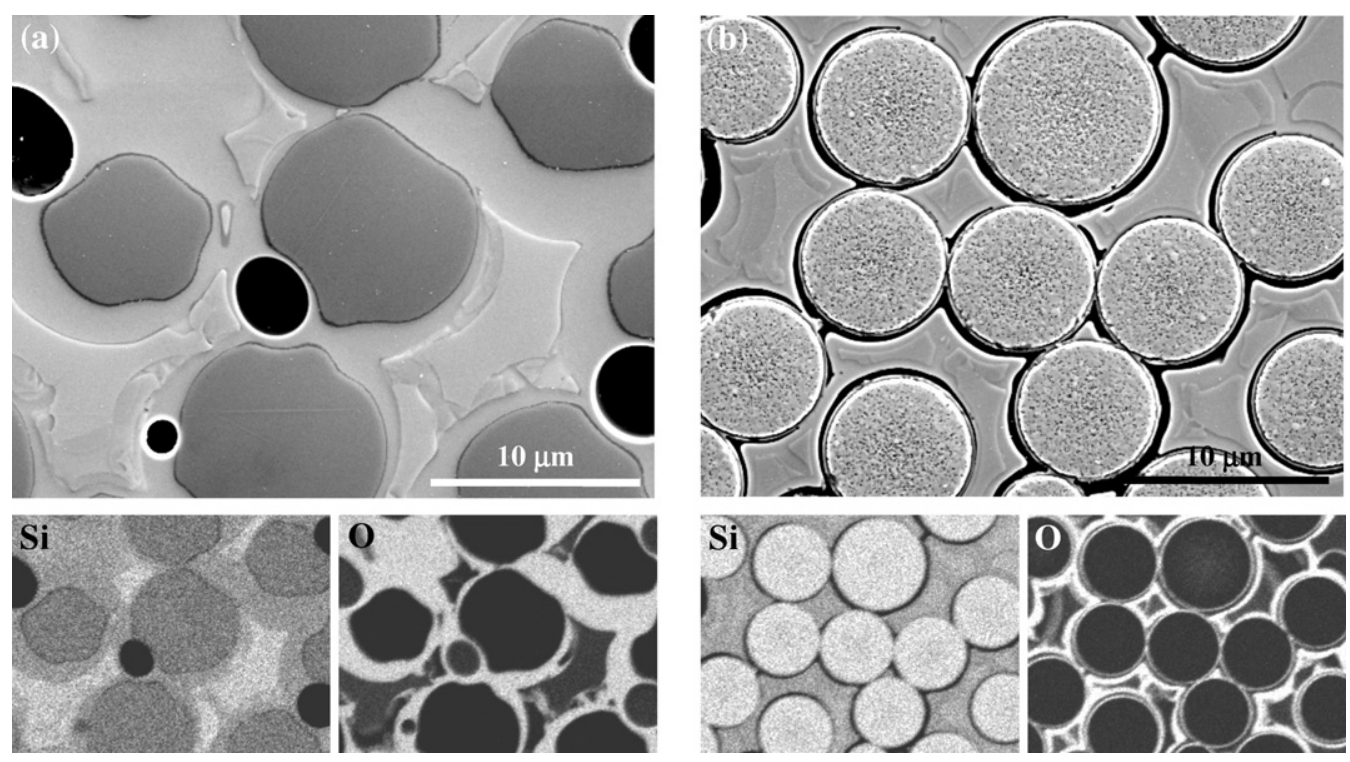

Fig. 13. EDS-mapping for $0 \mid 90^{\circ} \mathrm{UD}$ cross-ply layer reinforced CMCs after exposure to air $\left(T=1100^{\circ} \mathrm{C}, t=20 \mathrm{~h}\right.$ ): (a) $\mathrm{SiBNC}_{\mathrm{pyc}} / \mathrm{SiCN},(\mathrm{b}) \mathrm{SiC}$ pyc $/ \mathrm{SiCN}$ (Tyranno SA $3^{\mathrm{TM}}$ ). Grey colour indicates location of dedicated element. 

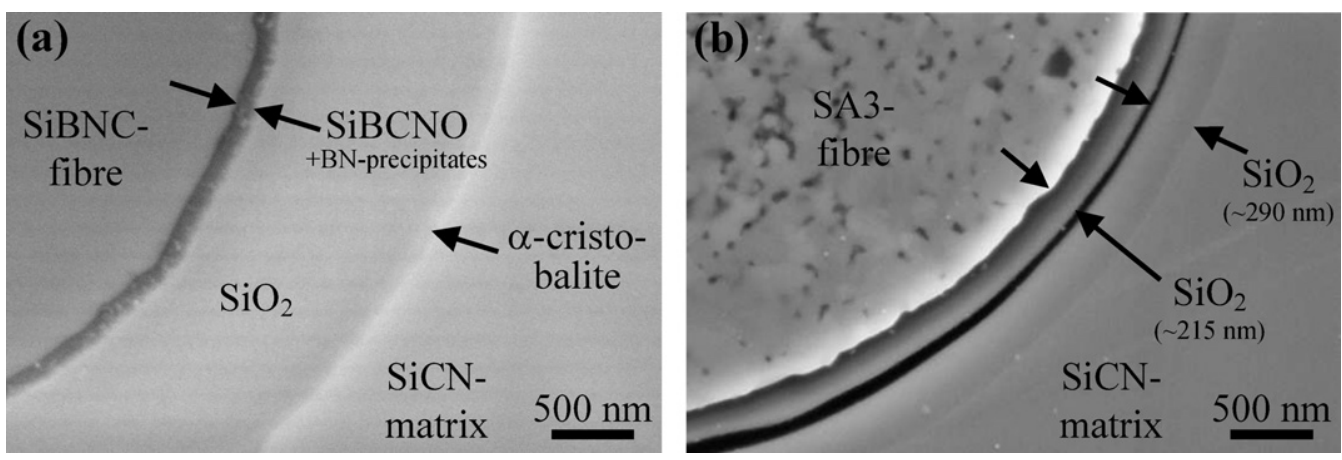

Fig. 14. Fibre/matrix interphase of (a) $\mathrm{SiBNC}_{\mathrm{pyc}} / \mathrm{SiCN}$ and (b) $\mathrm{SiC}_{\mathrm{pyc}} / \mathrm{SiCN}$ after exposure to air $\left(T=1100^{\circ} \mathrm{C}, t=20 \mathrm{~h}\right)$.

time of exposure to air at high temperatures, e.g. a decrease in fibre tensile strength of $\sim 50 \%$ and $\sim 85 \%$ at $1300{ }^{\circ} \mathrm{C}(1 \mathrm{~h})$ and $1.400{ }^{\circ} \mathrm{C}(15 \mathrm{~min})$, respectively, could be observed. ${ }^{34}$ The increase of fibre/matrix bonding due to massive silica formation caused by less oxidation resistance of SiBNC-fibres as well as the strong decrease of fibre tensile strength are the main reasons for strong decrease of mechanical performance of $\mathrm{SiBNC}_{\mathrm{pyc}} / \mathrm{SiCN}$ after exposure to air (ref. Fig. 10).

In contrast to $\mathrm{SiBNC}_{\text {pyc }} / \mathrm{SiCN}$, in $\mathrm{SiC}_{\text {pyc }} / \mathrm{SiCN}$ the gap between fibres and matrix (caused by active oxidation of pyc) is not closed by silica formation for most of the filaments (Figs. 12d, 13b and 14b). This is associated with lower fibre/matrix bonding compared to $\mathrm{SiBNC}_{\text {pyc }} / \mathrm{SiCN}$ leading to lower decrease of mechanical performance (Fig. 10) as well as less embrittlement of $\mathrm{SiC}_{\mathrm{pyc}} / \mathrm{SiCN}$ with respect to fracture behaviour (Fig. 11d) after exposure to air. The formation of silica occurred at the $\mathrm{SiC}$-fibres as well as the $\mathrm{SiCN}$-matrix (Fig. 14b). The thickness of silica on SiCN-matrix and Tyranno SA3 ${ }^{\mathrm{TM}}$ filaments was measured at $\sim 290 \mathrm{~nm}$ and $\sim 215 \mathrm{~nm}$, respectively. Mogilevsky et al. reported that silica formation on $\mathrm{SiC}$-fibres is strongly influenced by water vapour in laboratory air, e.g. silica formation on Tyranno SA $3^{\mathrm{TM}}$ fibres after exposure $\left(T=1200^{\circ} \mathrm{C}, t=10 \mathrm{~h}\right)$ to laboratory air with a water vapour content of $\sim 1-1.6 \%$ (silica thickness $\sim 700 \mathrm{~nm}$ ) is approximately 2.75 times higher compared to that in dry air (silica thickness $\sim 250 \mathrm{~nm}) .{ }^{49}$

Considering water vapour content in the laboratory air of $\sim 2.7 \%$ in this study, a measured silica thickness of $\sim 215 \mathrm{~nm}$ on Tyranno $\mathrm{SA} 3^{\mathrm{TM}}$ fibres in $\mathrm{SiC}_{\text {pyc }} / \mathrm{SiCN}$ after exposure to air $\left(T=1100^{\circ} \mathrm{C}, t=20 \mathrm{~h}\right)$ is in the same range as silica thicknesses reported for single fibres in dry air. Mogilevski et al. reported parabolic rate constants $\left(K_{\mathrm{p}}\right)$ of $30 \mathrm{~nm}^{2} / \mathrm{min}$ for oxidation of Tyranno SA3 ${ }^{\mathrm{TM}}$ fibres at a temperature of $1100^{\circ} \mathrm{C}$ (exposure time: $\leq 20 \mathrm{~h}$, dry air: $\leq 5 \mathrm{ppm} \mathrm{H}_{2} \mathrm{O}$ ). ${ }^{49}$ Taken this into account, silica with a thickness of $\sim 190 \mathrm{~nm}$ formed after $20 \mathrm{~h}$ at $1100^{\circ} \mathrm{C}$ in dry air which is slightly lower than silica thickness measured in this study for an atmosphere with $\sim 2.7 \%$ water vapour content. Hence, in spite of full active oxidation of pyc-fibre coating, SiC-fibres being embedded in a relatively dense SiCN-matrix exhibit a significantly lower silica formation (at least 1/3) compared to single fibres without matrix. Silica formation on $\mathrm{SiC}$-fibres is associated with fibre strength degradation. ${ }^{49-54}$ Thus, the decrease of bending and tensile strength of $\mathrm{SiC}_{\mathrm{pyc}} / \mathrm{SiCN}$ after exposure to air is mainly caused by fibre strength degradation as well as increase of fibre/matrix bonding due to silica formation.

The formation of silica (Young's modulus $~ 70-80 \mathrm{GPa}$ ) strongly affected the stiffness of SiBNC-fibre reinforced CMCs. Due to the considerable silica formation (combined with very strong fibre/matrix bonding), the fibre-dominated CMC before exposure changed to a matrix-dominated CMC after exposure to air. For SiBNC-fibre reinforced CMCs, a significant increase of Young's modulus (from $32 \mathrm{GPa}$ before exposure to $65 \mathrm{GPa}$ after exposure) could be observed whereas the Young's modulus of SiC-fibre reinforced CMCs slightly decreased after exposure (Fig. 10c). The reason is that for $\mathrm{SiC}_{\mathrm{pyc}} / \mathrm{SiCN}$ there are still gaps between fibre and matrix after exposure which means that fibres still dominate CMC properties. The slight decrease of stiffness for $\mathrm{SiC}_{\mathrm{pyc}} / \mathrm{SiCN}$ might be the result from the annular clearance around $\mathrm{SiC}$-fibres due to full oxidation of pyc-fibre coating.

From the comparison of mechanical properties (Fig. 10), crack propagation (Fig. 11c and d) and microstructure of $\mathrm{SiBNC}_{\text {pyc }} / \mathrm{SiCN}$ and $\mathrm{SiC}_{\text {pyc }} / \mathrm{SiCN}$ after exposure to air (Figs. 12c, d, 13 and 14) following correlation could be derived: The stronger the fibre/matrix bonding due to silica formation as a result of passive oxidation of fibre and matrix combined with the fibre strength degradation, the higher the loss in mechanical performance (tensile and bending strength, strain to failure and damage tolerance).

\subsection{Oxidation of CMC materials in air at high temperature via $T G A$}

During exposure to air at $1100^{\circ} \mathrm{C}$, active oxidation of pyc and passive oxidation of $\mathrm{SiC}, \mathrm{SiCN}$ and $\mathrm{SiBNC}$ occurred simultaneously. To separate active from passive oxidation and to quantify the weight loss and gain resulting from active and passive oxidation, respectively, TGAs were performed at different temperatures $\left(700^{\circ} \mathrm{C}\right.$ and $\left.1100^{\circ} \mathrm{C}\right)$ in flowing $(100 \mathrm{ml} / \mathrm{min})$ laboratory air for $20 \mathrm{~h}$ (Fig. 15). To quantify active oxidation of pyc-coating, TGA with $0 \mid 90^{\circ} \mathrm{UD}$ cross-ply layer reinforced $\mathrm{SiBNC}_{\text {pyc }} / \mathrm{SiCN}$ and $\mathrm{SiC}_{\text {pyc }} / \mathrm{SiCN}$ were conducted at $700{ }^{\circ} \mathrm{C}$ (continuous lines). The weight loss starts rapidly at temperatures above $\sim 500{ }^{\circ} \mathrm{C}$. After $\sim 300 \mathrm{~min}$, the main weight loss occurred which is $\sim 5 \mathrm{wt} . \%$ and $\sim 7.5 \mathrm{wt}$. $\%$ for $\mathrm{SiBNC}_{\text {pyc }} / \mathrm{SiCN}$ and $\mathrm{SiC}_{\text {pyc }} / \mathrm{SiCN}$, respectively. Despite of similar pyc-coating 


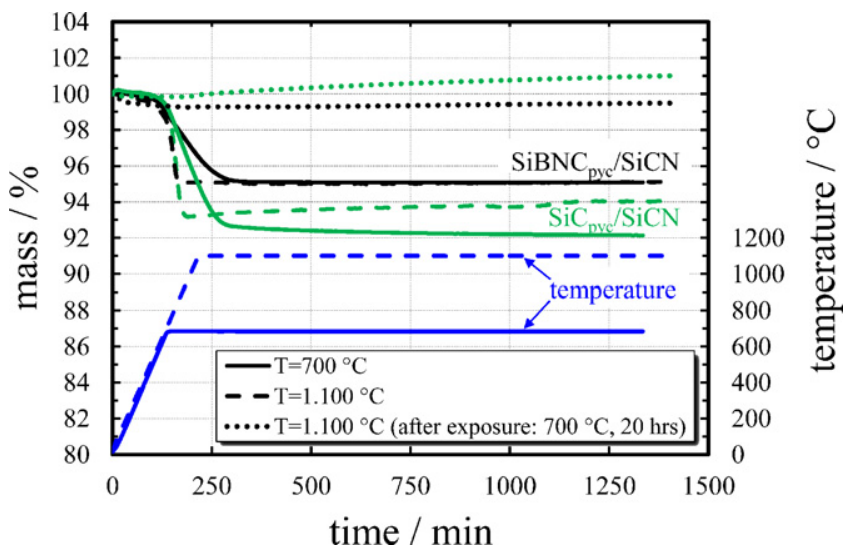

Fig. 15. TGAs of SiBNC- and $\mathrm{SiC}$-fibre reinforced (0|90 $\mathrm{SD}$ cross-ply layer) $\mathrm{CMCs}$ in laboratory air at $700^{\circ} \mathrm{C}$ and $1100^{\circ} \mathrm{C}$ (unexposed and after exposure to air at $700^{\circ} \mathrm{C}, 20 \mathrm{~h}$ ) for $20 \mathrm{~h}$.

thicknesses and higher density of SiC-compared to SiBNCfibre, the higher weight loss of $\mathrm{SiC}_{\mathrm{pyc}} / \mathrm{SiCN}$ is caused by higher volume content of pyc due to smaller fibre diameter of $\mathrm{SiC}$-fibres $(7.5 \mu \mathrm{m})$ compared to SiBNC-fibres $(10-12 \mu \mathrm{m})$ (ref. Table 1).

To quantify weight gain during passive oxidation separately from active oxidation, the same samples after TGA at $700{ }^{\circ} \mathrm{C}$ for $20 \mathrm{~h}$ were taken to perform a further TGA at $1100^{\circ} \mathrm{C}$ for $20 \mathrm{~h}$ (dashed lines). SiC-fibre reinforced $\mathrm{CMC}$ material exhibits a continuous increase of mass $(\sim 1 \mathrm{wt} . \%$ in $20 \mathrm{~h})$ caused by silica formation which is not finished after $20 \mathrm{~h}$. SiBNC-fibre reinforced CMC material shows nearly no mass change (decrease of $\sim 0.2 \mathrm{wt} . \%$ in $20 \mathrm{~h}$ ). Nevertheless, from microstructural analysis it is known, that massive silica formation occurred at $1100^{\circ} \mathrm{C}$ (Figs. 12c, 13a and 14a). No mass change might be the result from mass loss due to evaporation of $\mathrm{N}_{2}$ and $\mathrm{B}_{2} \mathrm{O}_{3}$ from $\mathrm{SiBNC}$ fibres ${ }^{29,30}$ compensated by mass gain due to silica formation.

Finally, TGAs with unexposed CMC materials were performed at $1100{ }^{\circ} \mathrm{C}$ for $20 \mathrm{~h}$ (dotted lines) where active and passive oxidation interfered with each other. For both fibre types, the mass loss is more rapid compared to TGAs at $700{ }^{\circ} \mathrm{C}$ and finished after $\sim 180 \mathrm{~min}$. For $\mathrm{SiC}_{\text {pyc }} / \mathrm{SiCN}$ the maximum weight loss is slightly lower to that at $700{ }^{\circ} \mathrm{C}$ due to interference of active oxidation of pyc with passive oxidation associated with mass gain (silica formation). For $\mathrm{SiBNC}_{\text {pyc }} / \mathrm{SiCN}$, the weight loss is similar to that at $700{ }^{\circ} \mathrm{C}$ caused by silica formation (=mass gain) being associated with evaporation of $\mathrm{N}_{2}$ and $\mathrm{B}_{2} \mathrm{O}_{3}$ (=mass loss).

\section{Conclusions}

On the basis of the data reported and discussed in Section 3, the following conclusions can be drawn:

(1) The number of PIP-cycles to obtain certain porosity is dependent on fibre architecture: CMCs based on plain weave fabric layer with highly ondulated fibres showed poor infiltration efficiency via RTM-process caused by inhomogeneous fibre volume content (fibre bundles and gussets) associated with inhomogeneous capillarity. Thus, plain weave fabric based CMCs needed three more PIPcycles (in total nine cycles) to obtain the same open porosity $\left(\sim 5\right.$ vol.\%) compared to $0 \mid 90^{\circ}$ UD cross-ply layer reinforced CMCs.

(2) Fibre architecture strongly influences pore distribution and average pore size in CMC materials manufactured via PIP-method: CMCs with plain weave fabric layer fibre reinforcement exhibit larger pores (average pore diameter $\sim 1.2 \mu \mathrm{m}$ at an open porosity of $\sim 5.2$ vol. $\%$ ) which are mainly located in gusset regions. In $0 \mid 90^{\circ}$ UD cross-ply layer fibre reinforced CMCs, pores are significantly smaller (average pore diameter $\sim 0.18 \mu \mathrm{m}$ at an open porosity of $\sim 4.3$ vol. $\%$ ) and well distributed.

(3) The influence of fibre architecture with respect to mechanical behaviour is much more significant in bending test compared to tensile test: bending strength of $0 \mid 90^{\circ} \mathrm{UD}$ cross-ply layer reinforced CMCs is nearly double compared to that of $0 \mid 90^{\circ}$ plain weave fabric fibre architecture caused by double fibre volume content (UD: all fibres are orientated in loading direction; plain weave: $50 \%$ of fibres are orientated in loading direction) in outer layer being under tensile load. In tensile test, both fibre architectures showed a very similar behaviour with respect to tensile strength, stiffness and strain to failure. Mechanical properties of unexposed CMC materials strongly correlate with fibre properties. Thus, $\mathrm{SiC}_{\text {pyc }} / \mathrm{SiCN}$ showed higher strength and stiffness but lower strain to failure compared to $\mathrm{SiBNC}_{\text {pyc }} / \mathrm{SiCN}$.

(4) After exposure to air $\left(1100^{\circ} \mathrm{C}, 20 \mathrm{~h}\right)$, mechanical properties decreased significantly for $\mathrm{SiC}$ - as well as SiBNC-fibre reinforced CMCs. Pyc-fibre coating oxidised completely (active oxidation) interfered with silica formation (passive oxidation) on fibres as well as $\mathrm{SiCN}$-matrix. SiBNC-fibres are less oxidation resistant than Tyranno SA3-fibres. Silica formation on $\mathrm{SiBNC}$-fibres (combined with vaporisation of $\mathrm{N}_{2}$ and $\mathrm{B}_{2} \mathrm{O}_{3}$ accelerated by water vapour $(\sim 2.7 \%)$ in laboratory air) was significantly higher compared to SiC-fibres. This is associated with higher fibre strength degradation of SiBNC-fibre and stronger fibre/matrix bonding in $\mathrm{SiBNC}_{\mathrm{pyc}} / \mathrm{SiCN}$ leading to higher decrease in mechanical performance after exposure to air compared to $\mathrm{SiC}_{\text {pyc }} / \mathrm{SiCN}$.

(5) Even in a relatively dense SiCN-matrix (open porosity of $\mathrm{CMC} \sim 5$ vol. $\%$ ), pyc-fibre coating oxidised very quickly $(\sim 3 \mathrm{~h})$ in air at $1100^{\circ} \mathrm{C}$. However, after complete oxidation of pyc-fibre coating $\mathrm{SiC}$-fibres being embedded in a relatively dense $\mathrm{SiCN}$-matrix exhibit a significantly lower silica formation (at least 1/3) compared to single fibres without matrix.

To improve the oxidation resistance of $\mathrm{SiC}$ - and $\mathrm{SiBNC}$-fibre based CMC materials manufactured via PIP-process, an additional environmental barrier coating (EBC) and/or an oxidation resistant fibre coating is required. The focus for future work will be the development of an oxidation resistant fibre coating. 


\section{Acknowledgements}

This work was financially supported by Federal Ministry of Education and Research (BMBF) within SiPEVe project (BMBF contract no. 03X3514H). The authors gratefully acknowledge Fraunhofer Institute of Silicate Research (ISC, Würzburg, Germany) for providing SiBNC-fibres, Clariant Advanced Materials GmbH (Sulzbach, Germany) for supplying polysilazane precursor, CVT GmbH \& Co. KG (Halblech, Germany) as well as Schunk Kohlenstofftechnik $\mathrm{GmbH}$ (Heuchelheim, Germany) for providing pyc-fibre coating on SiC- and SiBNCfibres and Mrs Gudrun Steinhilber (German Aerospace Center, Stuttgart, Germany) for conducting mercury intrusion porosimetry measurements.

\section{References}

1. Brewer D. HSR/EPM combustor materials development program. J Mater Sci Eng 1999;A261:284-91.

2. Doyle A. CFM finalises Leap-X engine architecture. Flight International; 2009.

3. Filsinger D, Münz S, Schulz A, Wittig S, Andrees G. Experimental assessment of fiber-reinforced ceramics for combustor walls. J Eng Gas Turbines Power 2001;123:271-6.

4. Kimmel J, Miriyala N, Price J, More K, Tortorelli P, Eaton H, Linsey G, Sun E. Evaluation of CFCC liners with EBC after field testing in a gas turbine. J Eur Ceram Soc 2002;22:2769-75.

5. Murthy P, Nemeth N, Brewer D, Mital S. Probabilistic analysis of a $\mathrm{SiC} / \mathrm{SiC}$ ceramic matrix composite turbine vane. Composites Part B 2008;39:694-703.

6. Lamouroux F, Bouillon E, Cavalier J, Spriet P, Habarou G. An improved long life duration CMC for jet aircraft engine applications. In: Krenkel W, Naslain R, Schneider H, editors. High temperature ceramic matrix composites. Weinheim, Germany: Wiley-VCH Verlag GmbH \& Co. KgaA; 2001. p. 783-8.

7. Lee KN, Fox D, Eldridge J, Zhu DM, Robinson R, Bansal NP, Miller R. Upper temperature limit of environmental barrier coatings based on Mullite and BSAS. J Am Ceram Soc 2003;86(8):1299-309.

8. Ohnabea H, Masakia S, Onozukaa M, Miyaharab K, Sasab T. Potential application of ceramic matrix composites to aero-engine. Composites Part A 1999;30:489-96.

9. Tanamura T, Nakamura T, Takahashi K, Araki T, Natsumura T. Research of CMC application to turbine components. IHI Eng Rev 2005;38(2):58-62.

10. Sato K, Tezukaa A, Funayamaa O, Isoda T, Teradab Y, Katob S, Iwata $\mathrm{M}$. Fabrication and pressure testing of a gas-turbine component manufactured by a preceramic-polymer-impregnation method. Compos Sci Technol 1999;59:853-9.

11. Roode M, Price J, Kimmel J, Miriyala N, Leroux D, Fahme A, Smith K. Ceramic matrix composite combustor liners: a summary of field evaluations. J Eng Gas Turb Power 2007;129:21-30.

12. Naslain R. Processing of non-oxide ceramic matrix composites: an overview. Adv Sci Technol 2006;50:64-74.

13. Naslain R. Processing of ceramic matrix composites. Key Eng Mater 1999;164-165:3-10.

14. Naslain R, Langlais F, Fedou R. The CVI-processing of ceramic matrix composites. J Phys 1989;C5(05):191-207.

15. Corman G, Luthra K. Silicon melt infiltrated ceramic composites (HiPerComp TM). In: Bansal NP, editor. Handbook of ceramic composites. Springer-Verlag, New York Inc; 2005. p. 99-115 [Chapter 5].

16. Motz G, Schmidt S, Beyer S. The PIP-process: precursor properties and applications. In: Krenkel W, editor. Ceramic matrix composites - fiber reinforced ceramics and their applications. Weinheim, Germany: Wiley-VCH GmbH \& Co. KGaA; 2008. p. 165-86 [Chapter 7].

17. Schäfer W, Vogel W. Fiber reinforced ceramics manufactured via polymerinfiltration (in German). In: Krenkel W, editor. Ceramic matrix composites.
Weinheim, Germany: Wiley-VCH Verlag GmbH \& Co. KGaA; 2003. p. 76-94.

18. Greil P. Near-net-shape manufacturing of polymer derived ceramics. $J$ Eur Ceram Soc 1998;18:1905-14.

19. Colombo P, Mera G, Riedel R, Sorarù X. Polymer-derived ceramics: 40 years of research and innovation in advanced ceramics. J Am Ceram Soc 2010;93(7):1805-37.

20. Matsumoto RLK. Crystallization of pyrolyzed polysilazanes. Mater Res Soc Symp Proc 1990;180:797-800.

21. Schwark J, Sullivan M. Isocyanate-modified polysilazanes conversion to ceramic materials. Mater Res Soc Symp Proc 1992;271:807-12.

22. Iwamoto Y, Völger W, Kroke E, Riedel R. Crystallization behavior of amorphous silicon carbonitride ceramics derived from organometallic precursors. J Am Ceram Soc 2001;84(10):2170-8.

23. KION Corporation. Technical Bulletin (TB2): KiON ceraset polyureasilazane and $\mathrm{KiON}$ ceraset polysilazane 20 - ceramic precursor applications. Pennsylvania, USA: Huntingdon Valley.

24. Janakiraman N, Aldinger F. Fabrication and characterization of fully dense $\mathrm{Si}-\mathrm{C}-\mathrm{N}$ ceramics from a poly(ureamethylvinyl)silazane precursor. $J$ Eur Ceram Soc 2009;29:163-73.

25. Stantschev G, Frieß M, Kochendörfer R, Krenkel W. Manufacture and properties of long fiber reinforced ceramics containing Al- and Ti-fillers based on the PIP process. In: Proceedings of 5th international conference on high temperature ceramic matrix composites HT-CMC 5. 2004.

26. Stantschev G, Frieß M, Kochendörfer R, Krenkel W. Long fibre reinforced ceramics with active fillers and a modified intra-matrix bond based on the LPI process. J Eur Ceram Soc 2005;25:205-9.

27. Baldus $\mathrm{H}$, Wagner $\mathrm{O}$, Jansen M. Synthesis of advanced ceramics in the system $\mathrm{Si}-\mathrm{B}-\mathrm{N}$ and $\mathrm{Si}-\mathrm{B}-\mathrm{N}-\mathrm{C}$ employing novel precursor compounds. Mater Res Soc Symp Proc 1992;271:821-6.

28. Baldus H, Jansen M, Wagner O. New materials in the system Si-(N, C)-B and their characterization. Key Eng Mater 1994;89(91):75-9.

29. Baldus H, Passing G, Sporn D, Thierauf A. Si-B-(N, C) a new ceramic material for high performance applications. Ceram Trans 1995;58:75-84.

30. Baldus H, Jansen M, Sporn D. Ceramic fibers for matrix composites in high-temperature applications. Science 1999;285:699-703.

31. Baldus H, Jansen M. Novel high-performance ceramics - amorphous inorganic networks from molecular precursors. Angew Chem Int Ed 1997;36(4):328-43.

32. Baldus H, Jansen M. Modern high performance ceramics - amorphous anorganic networks from molecular precursors. Angew Chem 1997;109:338-54 [in German].

33. Riedel R, Ruswisch L, An L, Ray R. Amorphous silicoboron carbonitride ceramic with very high viscosity at temperatures above $1500^{\circ} \mathrm{C}$. J Am Ceram Soc 1998;81(12):3341-4.

34. Cinibulk M, Parthasarathy T. Characterization of oxidized polymer-derived SiBNC fibers. J Am Ceram Soc 2001;84(10):2197-202.

35. Noeth A. Development and characterization of high performance SiBN3C fibers. In: Poster presentation of 7th int. conf. on high temperature ceramic matrix composites HT-CMC7. 2010.

36. He M, Hutchinson J. Kinking of a crack out of an interface. J Appl Mech 1989;56:270-8.

37. UBE Industries Ltd. Tyranno fiber (product catalogue). Available at: http://www.upilex.jp/e_ceramic.html.

38. Weiß R, Zimova M, Herborn R, Spaniol H, Klatt E, Hegermann R, Wilhelmi C, Hausherr J, Braue W, Koch D, et al. Final report: SiBNC-materials for production, energy and transport applications (in German). SiPEVe, contract no. 03X3514 H. Germany: BMBF, Jülich; 2010.

39. Jones R, Szweda A, Petrak D. Polymer derived ceramic matrix composites. Composites Part A 1999;30:569-75.

40. Jacobson N. Corrosion of silicon-based ceramics in combustion environments. J Am Ceram Soc 1993;76(1):3-28.

41. Naslain R, Guette A, Rebillat F, Le Gallet S, Lamouroux F, Filipuzzi L, Louchet $\mathrm{C}$. Oxidation mechanisms and kinetics of SiC-matrix composites and their constituents. J Mater Sci 2004;39:7303-16.

42. Shimoo T, Morisada Y, Okamura K. Oxidation behavior of Si-C-O fibers (Nicalon) under oxygen partial pressures from $10^{2}$ to $10^{5} \mathrm{~Pa}$ at $1773 \mathrm{~K} . J$ Am Ceram Soc 2000;83(12):3049-56. 
43. Chollon G, Pailler R, Naslain R, Laanani F, Monthioux M, Olry P. Thermal stability of a PCS-derived SiC fibre with a low oxygen content (Hi-Nicalon). J Mater Sci 1997;32(2):327-47.

44. Shimoo T, Toyoda F, Okamura K. Oxidation kinetics of low-oxygen silicon carbide fiber. J Mater Sci 2000;35(13):3301-6.

45. Shimoo T, Okamura K, Morisada Y. Active-to-passive oxidation transition for polycarbosilane-derived silicon carbide fibers heated in $\mathrm{Ar}-\mathrm{O}_{2}$ gas mixtures. J Mater Sci 2002;37(9):1793-800.

46. Shimoo T, Takeuchi H, Takeda M, Okamura K. Oxidation kinetics and mechanical property of stoichiometric SiC fibers (Hi-Nicalon-S). J Ceram Soc Jpn 2000;108(12):1096-102.

47. Jacobson N, Farmer S, Moore A, Sayir H. High-temperature oxidation of boron nitride. I. Monolithic boron nitride. J Am Ceram Soc 1999;82(6): 1473-82.

48. Jacobson N, Morscher GN, Bryant D, Tressler R. High-temperature oxidation of boron nitride. II. Boron nitride layers in composites. J Am Ceram Soc 1999;82(2):393-8.
49. Mogilevsky P, Boakye E, Hay R, Welter J, Kerans R. Monazite coatings on SiC fibers. II. Oxidation protection. J Am Ceram Soc 2006;89(11): 3481-90.

50. Boakye E, Mogilevsky P, Parthasarathy T, Hay R, Welter J, Kerans R. Monazite coatings on $\mathrm{SiC}$ fibers. I. Fiber strength and thermal stability. $J \mathrm{Am}$ Ceram Soc 2006;89(11):3475-80.

51. Kim HE, Moorhead A. Strength of Nicalon silicon carbide fibers exposed to high-temperature gaseous environments. J Am Ceram Soc 1991;74(3):666-9.

52. Yoshimura Y. Low temperature oxidation, hydrothermal corrosion, and their effects on properties of $\mathrm{SiC}$ (Tyranno) fibers. $J$ Am Ceram Soc 1995;78(6): 1439-50.

53. Takeda M, Urano A, Sakamoto J, Imai Y. Microstructure and oxidative degradation behavior of silicon carbide fiber Hi-Nicalon type S. J Nucl Mater 1998;258-263:1594-9.

54. Takeda M. Microstructure and oxidation behavior of silicon carbide fibers derived from polycarbosilane. J Am Ceram Soc 2000;83(5):1171-6. 